\title{
Quantification of CO emissions from the city of Madrid using MOPITT satellite retrievals and WRF simulations
}

\author{
Iris N. Dekker ${ }^{1,2}$, Sander Houweling ${ }^{1,2, a}$, Ilse Aben ${ }^{1}$, Thomas Röckmann ${ }^{2}$, Maarten Krol ${ }^{1,2,3}$, Sara Martínez-Alonso ${ }^{4}$, \\ Merritt N. Deeter ${ }^{4}$, and Helen M. Worden ${ }^{4}$ \\ ${ }^{1}$ SRON Netherlands Institute for Space Research, Utrecht, the Netherlands \\ ${ }^{2}$ Institute for Marine and Atmospheric Research Utrecht, Utrecht University, the Netherlands \\ ${ }^{3}$ Department of Meteorology and Air Quality, Wageningen University and Research Centre, Wageningen, the Netherlands \\ ${ }^{4}$ National Center for Atmospheric Research (NCAR), Boulder, CO, USA \\ ${ }^{a}$ currently at: Vrije Universiteit Amsterdam, Department of Earth Sciences, Amsterdam, the Netherlands
}

Correspondence to: Iris N. Dekker (i.n.dekker@uu.nl)

Received: 4 May 2017 - Discussion started: 3 July 2017

Revised: 27 September 2017 - Accepted: 25 October 2017 - Published: 11 December 2017

\begin{abstract}
The growth of mega-cities leads to air quality problems directly affecting the citizens. Satellite measurements are becoming of higher quality and quantity, which leads to more accurate satellite retrievals of enhanced air pollutant concentrations over large cities. In this paper, we compare and discuss both an existing and a new method for estimating urban-scale trends in $\mathrm{CO}$ emissions using multiyear retrievals from the MOPITT satellite instrument. The first method is mainly based on satellite data, and has the advantage of fewer assumptions, but also comes with uncertainties and limitations as shown in this paper. To improve the reliability of urban-to-regional scale emission trend estimation, we simulate MOPITT retrievals using the Weather Research and Forecast model with chemistry core (WRFChem). The difference between model and retrieval is used to optimize CO emissions in WRF-Chem, focusing on the city of Madrid, Spain. This method has the advantage over the existing method in that it allows both a trend analysis of $\mathrm{CO}$ concentrations and a quantification of $\mathrm{CO}$ emissions. Our analysis confirms that MOPITT is capable of detecting $\mathrm{CO}$ enhancements over Madrid, although significant differences remain between the yearly averaged model output and satellite measurements $\left(R^{2}=0.75\right)$ over the city. After optimization, we find Madrid CO emissions to be lower by $48 \%$ for 2002 and by $17 \%$ for 2006 compared with the EdgarV4.2 emission inventory. The MOPITT-derived emission adjustments lead to better agreement with the European emission inventory TNO-MAC-III for both years. This suggests that
\end{abstract}

the downward trend in $\mathrm{CO}$ emissions over Madrid is overestimated in EdgarV4.2 and more realistically represented in TNO-MACC-III. However, our satellite and model based emission estimates have large uncertainties, around $20 \%$ for 2002 and $50 \%$ for 2006.

\section{Introduction}

During the last decades, global urbanization has led to an increase in the number of large cities. Several hundred cities currently have more than a million inhabitants. These highly populated cities with dense traffic networks are important sources of many kinds of air pollutants that directly affect the large fraction of the population living there (e.g., Pascal et al., 2013; Kan et al., 2012; Romero-Lankao et al., 2013). Therefore, global urbanization increases the need for air quality monitoring and prediction in large cities. Large cities are also important sources of several greenhouse gases (GHGs). A recent development in air quality and GHG monitoring is the use of sensors on board of satellites to augment ground-based measurement networks in cities. Especially in cities without a dense measurement network, satellite data can have an important added value. Thanks to improvements in the quality, spatial resolution and sampling of data from atmospheric composition sensors on board of satellites over the past decades, detection and quantification of city emissions is becoming feasible for an increasing number of air 
pollution species (Streets et al., 2013). Nitrogen oxides (NO and $\mathrm{NO}_{2}$, together called $\mathrm{NO}_{x}$ ) emissions from cities have been successfully quantified in several studies (e.g., Beirle et al., 2011; Liu et al., 2016). First steps have also been made to quantify urban emissions of other species such as sulfur dioxide using satellite observations (Fioletov et al., 2011). Urban carbon monoxide (CO) has also been studied (Pommier et al., 2013; Clerbaux et al., 2008; Worden et al., 2012). This paper focuses on quantifying urban $\mathrm{CO}$ emissions.

$\mathrm{CO}$ is a major air pollutant in cities. It is a toxic gas for humans at ground level at high concentration (but is usually detected at $<1 \mathrm{ppm}$ in most present-day urban environments). The World Health Organization recommends a maximum of $9 \mathrm{ppm} \mathrm{CO}$ for $8 \mathrm{~h}$ exposure (WHO, 2004). CO is an important precursor of tropospheric ozone and a primary control on the oxidizing power of the atmosphere. The primary sink of $\mathrm{CO}$ is the hydroxyl radical $(\mathrm{OH})$. The lifetime of $\mathrm{CO}$ varies between several weeks and several months, depending on the location and season (e.g., Holloway et al., 2007; Khalil and Rasmussen, 1990). The relatively long lifetime compared to some other air pollutants results in a rather smooth spatial distribution. Therefore the difference in concentration between the background atmosphere and regions close to sources is smaller than for $\mathrm{NO}_{x}$, which has a lifetime of hours to days. This makes $\mathrm{CO}$ sources harder to detect and quantify than $\mathrm{NO}_{x}$ sources. On the other hand, urban $\mathrm{CO}$ is easier to detect than urban carbon dioxide and methane, for example, which have lifetimes of several years to decades, leading to well-mixed distributions and relatively small source signals. Due to its intermediate lifetime, $\mathrm{CO}$ can be a good tracer of pollution transport and has been used, for example, as a proxy for anthropogenic emissions of the important GHG carbon dioxide (Gamnitzer et al., 2006). The increasing availability of $\mathrm{CO}$ measurements from Earth orbiting satellites raises the interest in the use of remote sensing for studying urban $\mathrm{CO}$ emissions.

The Measurement Of Pollution In The Troposphere (MOPITT) remote sensing instrument, on board the NASA Terra satellite, has been measuring global $\mathrm{CO}$ concentrations since March 2000. The added value of MOPITT compared to other satellite instruments is that it can retrieve CO not only in the thermal infrared $(\sim 4.7 \mu \mathrm{m})$ but also in the near infrared $(\sim 2.3 \mu \mathrm{m})$ wavelengths, which together provide an improved sensitivity to $\mathrm{CO}$ near the Earth's surface (Worden et al., 2010; Deeter et al., 2009). ESA's TROPOspheric Monitoring Instrument (TROPOMI) instrument, to be launched in 2017 on the Sentinel 5 precursor satellite, will also measure $\mathrm{CO}$ concentrations in this shorter wavelength range around $2.3 \mu \mathrm{m}$ (Landgraf et al., 2016; Fu et al., 2016; Abida et al., 2017). The TROPOMI spatial resolution, $7 \times 7 \mathrm{~km}^{2}$ at nadir and daily global coverage will be increased considerably compared to MOPITT, which has $22 \times 22 \mathrm{~km}^{2}$ spatial resolution and global coverage once every $2-3$ days (Edwards et al., 2004), making it even more suitable for city emission estimation.
So far, satellite retrievals of $\mathrm{CO}$ have been used mainly in global-scale analyses, quantifying large-scale $\mathrm{CO}$ emissions (e.g., Hooghiemstra et al., 2012a, b; van Leeuwen et al., 2013; Girach and Nair, 2014; Yin et al., 2015; Jiang et al., 2017) with a primary interest in biomass burning. Furthermore, the first attempts have been made to use MOPITT CO retrievals to estimate emission changes over cities (Pommier et al., 2013). Clerbaux et al. (2008) and Pommier et al. (2013) already demonstrated that CO pollution plumes over large cities can be distinguished from the background in satellite data. However, averaging over long time periods was necessary to reduce measurement noise. In addition, Pommier et al. (2013) calculated relative trends in $\mathrm{CO}$ emissions from changes in the observed $\mathrm{CO}$ enhancement over cities in time. However, to move from this estimation of relative trends to the quantification of the emissions requires additional information on atmospheric dispersion.

The aim of this work is to estimate $\mathrm{CO}$ emissions from cities by quantifying the relationship between local concentration enhancements and emissions, making use of the Weather Research and Forecasting (WRF) model together with the MOPITT retrievals. The method is developed in a way that can easily be applied to other satellite data such as TROPOMI data; we expect the robustness of the method to increase when used with the higher sampling and finer spatial resolution of the TROPOMI data. We test the performance of this method in comparison with the method for estimating emission trends using only satellite data of Pommier et al. (2013), which we will refer to as the "satelliteonly" method, focusing on specific aspects that can influence the estimation of emission trends using the satellite-only method that do not influence the emission estimation in our own method.

For the satellite-only method, we investigated nine target cities: Baghdad, Delhi, Los Angeles, Mexico City, Moscow, Paris, Sao Paulo, Tehran and Madrid. For our new method, referred to as "WRF optimization", we focus on the city of Madrid. Madrid is a source for which two high-resolution emission inventories are available (Kuenen et al., 2014; Crippa et al., 2016) and which, due to its climate and isolated position from other sources, has relatively favourable conditions for the retrieval of $\mathrm{CO}$ using MOPITT; this makes Madrid well suited for developing and testing the new method.

This paper is organized as follows: Sect. 2 describes the MOPITT data and two methods to estimate emission (trends): the satellite-only method and our own WRF optimization technique. It also includes a brief description of the WRF model. We then present results based on the satellite-only technique (Sect. 3.1), and analyze its limitations (Sect. 3.2). Next we describe the results of the WRF optimization method (Sect. 3.3) and analyze its limitations (Sect. 3.4). A summary and conclusions are presented in Sect. 4. Additional text, figures and tables can be found in the Supplement. 


\section{Data and methods}

\subsection{MOPITT CO retrieval}

MOPITT, on board the NASA Terra satellite, has been operating almost continuously since it was launched in December 1999 in a sun synchronous orbit with local equator crossing times of approximately 10:30 and 22:30 (Edwards et al., 2004). Data are available from March 2000 onwards. The size of pixels is $22 \mathrm{~km} \times 22 \mathrm{~km}$ at nadir. The MOPITT swath is formed by scanning a four-pixel linear detector array across the satellite track and covers a total width of approximately $640 \mathrm{~km}$. Neglecting the effects of clouds, nearglobal coverage takes about 3 days (Edwards et al., 2004). The MOPITT instrument uses gas correlation radiometry to determine CO concentrations (Deeter et al., 2003). It has several instrument channels that sense infrared radiation (IR). The original MOPITT thermal infrared (TIR, $\sim 4.7 \mu \mathrm{m}$ ) retrieved $\mathrm{CO}$ data set, has been expanded with near-infrared (NIR, $\sim 2.3 \mu \mathrm{m}$ ) retrievals (Deeter et al., 2009) and a combined NIR and TIR (hereafter called multispectral) product has been derived, with improved sensitivity to $\mathrm{CO}$ near the Earth's surface (Worden et al., 2010; Deeter et al., 2009). The multispectral product combines the best features of both retrievals: higher sensitivity in the lower troposphere over land from the NIR, and vertical information in the free troposphere from the TIR (Deeter et al., 2013, 2014). The NIR channel adds most information in the lower troposphere and over land scenes with low thermal contrast (e.g., moist vegetation; Deeter et al., 2009). As the goal of our method requires maximum sensitivity to $\mathrm{CO}$ in the lower troposphere, we will mostly use the multispectral $\mathrm{CO}$ retrievals.

For this research, MOPITT version 6 (and for comparisons with Pommier et al., 2013, version 5) level 2 data were used for the period March 2000-December 2008 (Deeter, 2013a). The data of version 5 have been validated extensively (e.g., Deeter et al., 2013; de Laat et al., 2014), and version 6 data have been validated by Deeter et al. (2014, 2016). The validation results show that the version 6 data have reduced retrieval bias in the upper troposphere and confirm that the joint NIR and TIR product has enhanced sensitivity to CO in the lower troposphere compared to the TIRonly product. However, a negative concentration bias over the Amazon basin was reported in the version 6 multispectral product (Deeter et al., 2016). In version 6, compared to the previous version 5 data, a geolocation bias has been corrected (Deeter et al., 2014), and meteorological fields are derived from NASA MERRA instead of NCEP (Deeter et al., 2014). Monthly varying a priori data in version 6 are based on the CAM-CHEM model climatology for 2000-2009 gridded on $1^{\circ} \times 1^{\circ}$ (Deeter, 2013a), instead of the coarser gridded MOZART climatology used in V5 and V4.

When using version 5 of the data, we corrected for the location bias in longitude using the formula also applied by Pommier et al. (2013, see Eq. 1). This method might give slightly different corrections from the corrections the MOPITT team applied to version 6 of the data (Deeter, 2012), especially in the temperate zones:

$\operatorname{long}_{\text {new }}=\operatorname{long}_{\text {orig }}+0.33 \times \cos \left(\right.$ lat $\left._{\text {orig }}\right)$.

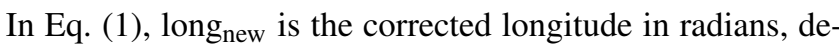
rived from the original coordinates (long $_{\text {orig }}$, lat ${ }_{\text {orig }}$; in radians). The NIR, TIR and combined multispectral data sets are made available on 10 pressure levels (surface to $900 \mathrm{hPa}$ and $900 \mathrm{hPa}$ to $100 \mathrm{hPa}$ in $100 \mathrm{hPa}$ intervals). Generally, the NIR product compared to the TIR product has relatively large random errors, requiring significant spatial and/or temporal averaging (Deeter, 2013b). The MOPITT retrieval, especially the TIR part, has a varying vertical sensitivity. The monthly varying a priori $\mathrm{CO}$ climatology constrains the retrieved profile. The relative weights of the true atmospheric profile and a priori profile are represented by the averaging kernel (AK) matrix, which is made available for every retrieval. The relationship between the retrieved volume mixing ratio (VMR) profile $\left(\boldsymbol{x}_{\mathrm{rtr}}\right)$, true VMR profile $\left(\boldsymbol{x}_{\text {true }}\right)$, a priori profile $\left(\boldsymbol{x}_{\mathrm{a}}\right)$ and averaging kernel matrix (AK) is given by

$\log _{10}\left(\boldsymbol{x}_{\text {retr }}\right)=\log _{10}\left(\boldsymbol{x}_{\mathrm{a}}\right)+\mathbf{A K}\left(\log _{10}\left(\boldsymbol{x}_{\text {true }}\right)-\log _{10}\left(\boldsymbol{x}_{\mathrm{a}}\right)\right)$.

The equation is logarithmic as the MOPITT retrieval algorithm assumes log-normal statistics for $\mathrm{CO}$ variability (Deeter, 2013a). Only daytime (solar zenith angle $<80^{\circ}$ ) and land pixels were used in this study, to avoid a strongly varying influence of the NIR channel in the multispectral retrieval. In addition, retrievals were filtered for clouds, keeping data with a cloud description diagnostic value of 1 or 2 . The cloud description diagnostic value is based on combined signals from MOPITT and MODIS (Moderate Resolution Imaging Spectrometer, also on board of Terra) on cloud coverage, with a value of 1 indicating clear-sky conditions according to MOPITT without information from MODIS, and a value of 2 indicating cloud-free according to MOPITT and MODIS

Due to the large pixel size of the MOPITT data relative to the size of cities, the long revisit time of the satellite, and the filtering on cloud-free and daytime scenes, the number of useful data over individual cities was limited. Because the path of the urban pollution plume and background concentration field both vary strongly with meteorological conditions, it was necessary to average the MOPITT data temporally and spatially over a substantial time period to distinguish an urban signal from the background. The averaging technique of Fioletov et al. (2011) was used for improving the spatial resolution, as described in the next paragraph.

\subsection{Emission estimation: satellite-only}

The work of Pommier et al. (2013), hereafter referred to as P13, served as starting point for our own analysis. A brief description of their method is given below. In P13, aver- 
ages were made over, respectively, 4 and 5 years to analyze the concentrations change from period 1 (2000-2003) to period 2 (2004-2008) for eight large cities. In order to distinguish cities, besides the temporal averaging also spatial averaging was applied, using the spatial oversampling technique of Fioletov et al. (2011). For this satellite-only approach, a $200 \times 200 \mathrm{~km}^{2}$ area around the target city is mapped at $2 \times 2 \mathrm{~km}^{2}$ resolution, with each high-resolution grid cell representing the average value of all satellite data having their footprint center within $28 \mathrm{~km}$ distance of that cell. The pixels were rotated in the direction of the wind using the city center as a rotation point, to align the urban plumes in upwind-downwind direction. With this technique, the data were oversampled to prevent urban plumes of $\mathrm{CO}$ from being smoothed out during the spatiotemporal averaging, as described also in Streets et al. (2013). The difference between the average MOPITT retrieved upwind and downwind concentration was subsequently used as a proxy of emission strength. Further, the relative difference (RD) quantifies the relative change in the proxy of emission strength between the two time periods.

In our study, the same spatial averaging and wind rotation techniques were used. For the wind data, $3 \mathrm{~h}$ wind fields were used from the ERA Interim reanalysis project of the European Centre for Medium-Range Weather Forecasts (Berrisford et al., 2009). These fields were averaged at $1^{\circ} \times 1^{\circ}$ resolution and 60 hybrid sigma-pressure levels from the surface to the top of the atmosphere using the pre-processor that is used for generating wind fields for the global transport model TM5 (Krol et al., 2005). For each day, the wind direction was taken for the grid box in which the city center of the respective city is located and the time step closest to the local overpass time of MOPITT. An average wind direction was constructed over the lowest 15 hybrid pressure layers of the TM5 model, roughly representing the average wind direction in the planetary boundary layer (PBL) up to about $720 \mathrm{hPa}$. For every MOPITT overpass, the associated modelled wind direction was recorded. This procedure is close but not identical to P13, who used $0.75^{\circ} \times 0.75^{\circ}$ data from ECMWF averaged from the surface to $700 \mathrm{hPa}$.

The urban concentration enhancement was finally estimated according to P13. First, for the total column CO, wind rotations and averages were made for the two periods. The time-averaged emission proxy in molecules $\mathrm{cm}^{-2}$ was then calculated as the difference between the average of the five maximum downwind total columns $\left(\mathrm{CO}_{\text {totdownwind } i}\right.$; molec $\mathrm{cm}^{-2}$ ) minus the average of the five minimum upwind $\mathrm{CO}$ total columns $\left(\mathrm{CO}_{\text {totupwind } i} ;\right.$ molec $\left.\mathrm{cm}^{-2}\right)$ in a $20 \mathrm{~km}$ broad band from $100 \mathrm{~km}$ upwind to $100 \mathrm{~km}$ downwind of the city in the respective period, $V_{\mathrm{d}}-V_{\mathrm{u}}$, according to the equation of P13:

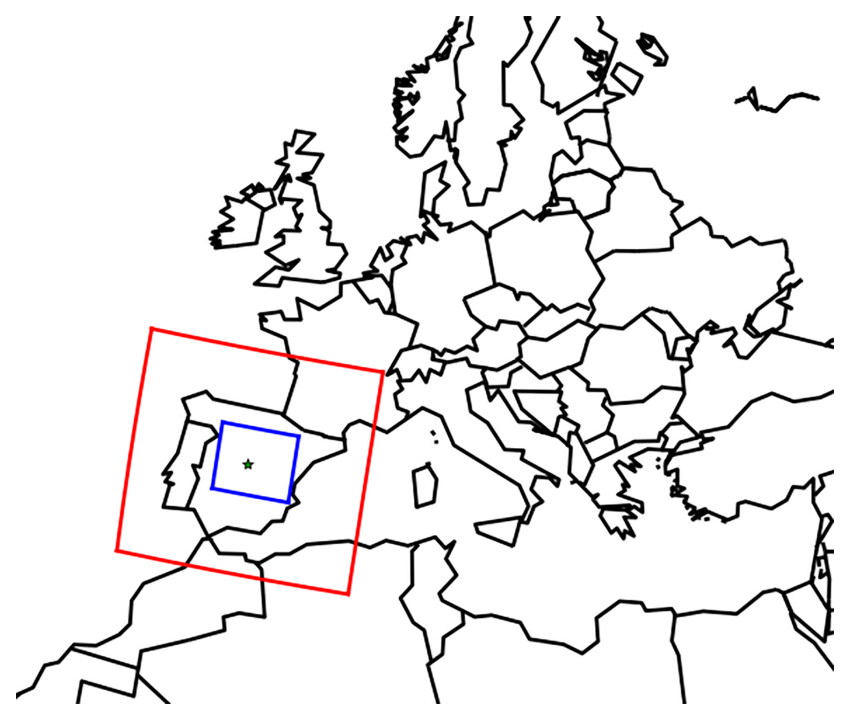

Figure 1. WRF domains d01 (red, $1500 \mathrm{~km} \times 1440 \mathrm{~km}$, resolution: $30 \times 30 \mathrm{~km}^{2}$ ) and $\mathrm{d} 02$ (blue, $490 \mathrm{~km} \times 430 \mathrm{~km}$, resolution: $10 \times 10 \mathrm{~km}^{2}$ ). The location of Madrid is shown by a green star.

downwind - upwind difference $=V_{\mathrm{d}}-V_{\mathrm{u}}=$

$\frac{\sum_{i=1}^{5} \max \left(\mathrm{CO}_{\text {totdownwind } i}\right)}{5}-\frac{\sum_{i=1}^{5} \min \left(\mathrm{CO}_{\text {totupwind } i}\right)}{5}$.

The standard deviations of the five highest downwind concentrations and of the five lowest upwind concentrations were calculated. The sum of these two standard deviations is used as the uncertainty in $V_{\mathrm{d}}-V_{\mathrm{u}}$. From $V_{\mathrm{d}}-V_{\mathrm{u}}$, the RD between period 1 and period 2 was calculated to estimate the trend in the concentration enhancement. The RD is defined as the change between the two periods with respect to period 1 and is expressed as a percentage.

\subsection{Emission estimation: WRF optimization}

To quantify emissions, additional information is required to determine the relation between emissions and concentrations, involving transport. To take this into account, we combined the satellite data with model data from the WRF model. We minimized the difference between the model and the satellite gridded data by changing the emissions in WRF to find the most probable emissions. The method will be described in more detail in this section.

\subsubsection{WRF model}

Model simulations of $\mathrm{CO}$ over Madrid were performed using the WRF model (http://www.wrf-model.org/) version 3.2.1, with the Advanced Research WRF core (ARW). WRF is a numerical non-hydrostatic model developed at the National Centers for Environmental Prediction (NCEP). It has several 

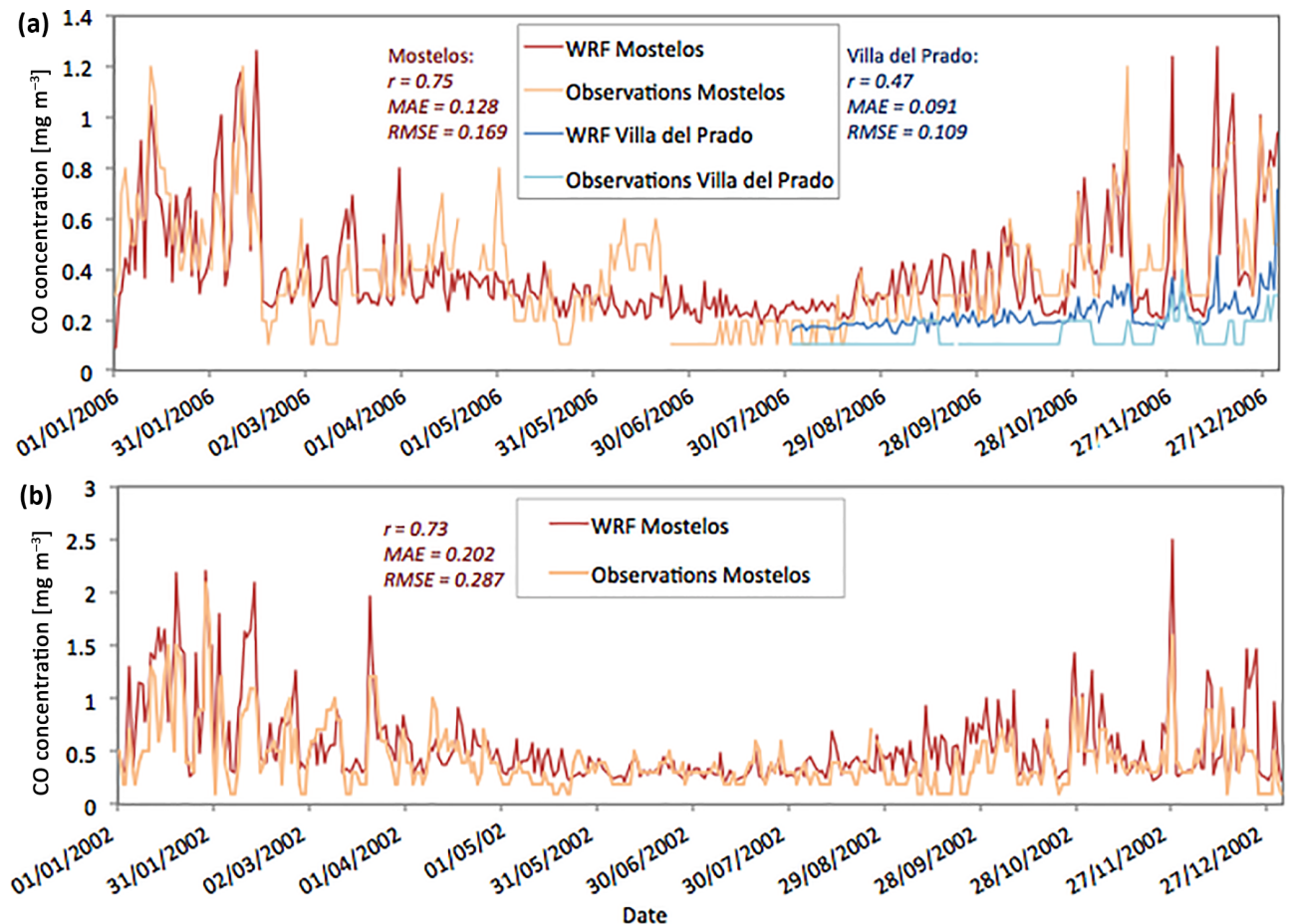

Figure 2. For 2006, above and 2002, below: daily averaged WRF surface concentrations (red and blue lines) compared to observations (orange and light blue lines) at two locations near Madrid.

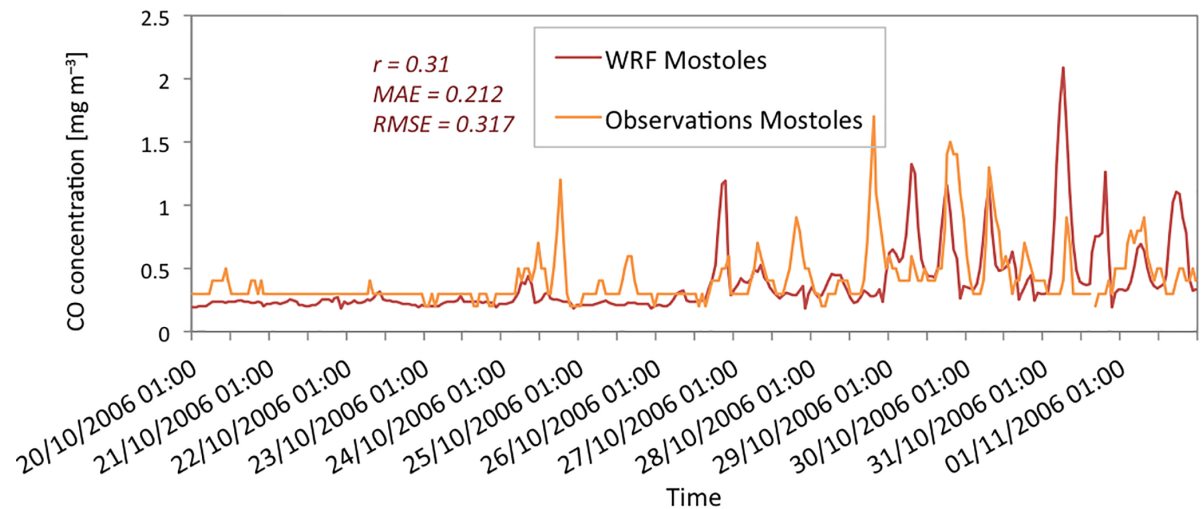

Figure 3. Hourly WRF surface concentrations (red line) compared to observations (orange line) at the Mostelos measurement station near Madrid for 10 days in October.

choices of physical parameterizations, which allows application of the model to a large range of spatial scales (Grell et al., 2005). For this study we used an updated version of the Yonsei University (YSU) boundary layer scheme (Hu et al., 2013), the Unified Noah land surface model for surface physics (Ek et al., 2003; Tewari et al., 2004), and the Dudhia scheme (Dudhia, 1989) and the Rapid Radiative Transfer Method (RRTM) for short-wave and long-wave radiation (Mlawer et al., 1997). Cloud physics are solved with the Grell-Freitas cumulus physics ensemble scheme (Grell and Freitas, 2014). A built-in application of WRF-ARW is WRF-Chem (Grell et al., 2005), which deals with chemi- cal processes and tracer transport. WRF-Chem is an online model, which means that the tracer transport is consistent with all conservative transport done by the meteorological model and that the chemistry can feedback on the dynamical computations. In this research, only the model's tracer transport function was used, not the encoded chemistry of WRF, to speed up the model. We considered this as a safe option, since the photochemical lifetime of $\mathrm{CO}$ is too long for its chemical degradation to play a significant role during transport across the city domain. For our Madrid case study, we set the model's outer domain to the Iberian Peninsula and part of the surrounding water bodies. This domain, 
modelled at a resolution of $30 \times 30 \mathrm{~km}^{2}$, defines boundary conditions for a nested subdomain with a model resolution of $10 \times 10 \mathrm{~km}^{2}$ covering an area of $490 \times 430 \mathrm{~km}^{2}$ around Madrid (Fig. 1). All the analyses in this paper were done for a sub-region of $200 \times 200 \mathrm{~km}^{2}$ around Madrid within this second domain. Our WRF simulations covered exactly 1 year, either 2002 or 2006. The time step used for calculations of dynamics and physics was 4 min in the outer domain and $80 \mathrm{~s}$ in the inner domain. We used 30 dynamic vertical pressure levels between the surface and $50 \mathrm{hPa}$. The $\mathrm{CO}$ boundary conditions of the outer domain were based on MOPITT profiles of climatological retrieved data. On each of the four lateral boundaries of the outer domain of WRF, the 9-year (2000-2008) average MOPITT CO concentration per month is taken over a half-degree zone adjacent to each boundary or the nearest land pixels of MOPITT. The data were interpolated to provide the vertical profile for all vertical layers of WRF. These four, monthly varying, profiles have been implemented into WRF as lateral boundary conditions for CO. This is considered sufficiently detailed, since the background concentrations will be scaled in our optimization technique and no significant background pattern is expected to come with the data, which is also confirmed in Sect. 3.5. The initial concentrations of $\mathrm{CO}$ within the domains were set to zero and are expected to adapt quickly to the boundary conditions by lateral transport. Initial and boundary conditions for meteorological parameters were based on data from the NCEP at a $1^{\circ} \times 1^{\circ}$ spatial and $6 \mathrm{~h}$ temporal resolution.

\subsubsection{Emission data sets}

$\mathrm{CO}$ emissions to use as prior estimates were taken from different anthropogenic emission inventories that are available for Madrid. For the years 2002 and 2006 we used emissions from the EdgarV4.2 inventory (available at a resolution of $0.1^{\circ} \times 0.1^{\circ}$ ) for the corresponding years (Crippa et al., 2016). We also used emissions from the European TNO-MACC inventory (Kuenen et al., 2014) with a spatial resolution of $0.125^{\circ} \times 0.0625^{\circ}$, for the years 2006 (version III) and 2007 (version II) in the sensitivity tests. All the emissions were regridded to the resolution of the WRF domains and account for monthly, weekly and hourly emission variations based on temporal emissions factors reported by van der Gon et al. (2011). More information on the different sectors included in the emission data sets can be found in the Supplement.

\subsubsection{Validation of WRF data}

To verify the performance of the model, we compared the model-simulated $\mathrm{CO}$ concentrations to available in situ measurements in Madrid (http://gestiona.madrid.org/azul_ internet/html/web/InformAnalizadoresAccion.icm, last access: 19 December 2016). CO concentration data are available for 2006 from two locations within our WRF domain: Mostelos, a station in a park in the south of Madrid and Villa del Prado, a background station in the Alberche Basin. For both locations the concentrations and patterns in concentrations appear very similar between WRF and the observations ( $r=0.75$ and $r=0.47$, respectively), although WRF overestimates the concentrations at the Villa del Prado station (Fig. 2, upper panel). The variation over the months with higher concentrations in winter is well represented. Most peaks seen in the observations are also found in the model and concentration differences between model and observation are generally within $0.1 \mathrm{mg} \mathrm{m}^{-3}$. It should be noted that the resolution of the observations is $0.1 \mathrm{mg} \mathrm{m}^{-3}$. Especially for the background station Villa del Prado, this resolution is close to the absolute value of the measurement $\left(0.1 \mathrm{mg} \mathrm{m}^{-3}\right.$ corresponds to about $\left.90 \mathrm{ppb}\right)$ and could thus be considered a bit coarse for measuring background concentrations. The overestimated CO concentration for the Villa del Prado station is considered reasonable, since with the resolution of $10 \times 10 \mathrm{~km}^{2}$ of WRF, the WRF pixel also includes two small towns in this area, while the station is measuring at a very remote location at the Villa del Prado station. On an hourly timescale, WRF also follows the observations quite well (Fig. 3, $r=0.31$ ) - stable low concentration patterns are also represented in the model as such, and higher concentrations with morning and afternoon peaks are also represented, although WRF is not able to see all peaks and some peaks are under- and overestimated (differences of up to $1 \mathrm{mg} \mathrm{m}^{-3}$ ). Given the limited resolution used in WRF and the difficulty of representing measurement sites in an urban environment, we consider the performance of WRF adequate to make a reasonable comparison with the coarser-resolution satellite data. For 2002, only data from the Mostelos station are available. In Fig. 2, lower panel, the comparison with these data is shown; both the peaks and the overall values match very reasonably $(r=0.73)$, the concentrations overlapping most of the time within $0.1 \mathrm{mg} \mathrm{m}^{-3}$.

\subsubsection{Comparing MOPITT and WRF}

The information of the MOPITT retrievals is not equally distributed over the 10 vertical levels, as mentioned earlier. For a fair comparison between satellite observations and model simulations, the AK matrix and a priori profile for each retrieval has been applied to the corresponding model output, ensuring a consistent vertical weighting of the model compared with the measurements. The MOPITT AK matrix was applied to the logarithm of model-simulated CO concentrations following Eq. (2), using the interpolated vertical model profile of CO from WRF as $\boldsymbol{x}_{\text {true }} \cdot \boldsymbol{x}_{\text {retr }}$ forms then the WRF vertical profile on MOPITT levels with the applied averaging kernel matrix that is used for comparison. In the comparison, average mixing ratios over all vertical MOPITT layers are used. For this method we only used MOPITT V6 data. 


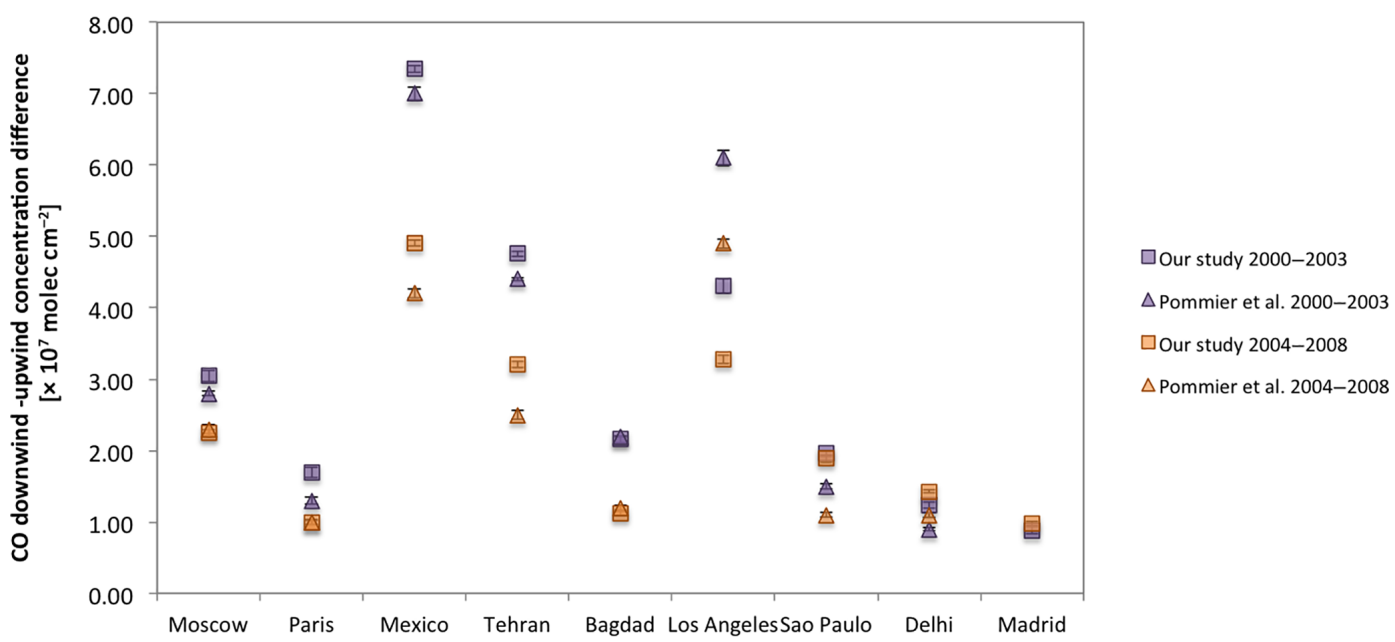

Figure 4. Total column CO concentration downwind minus upwind of selected cities (see Sect. 2), comparing our study using MOPITT version 5 (squares) and the study of Pommier et al. (2013, triangles). Error bars represent uncertainties calculated according to P13.

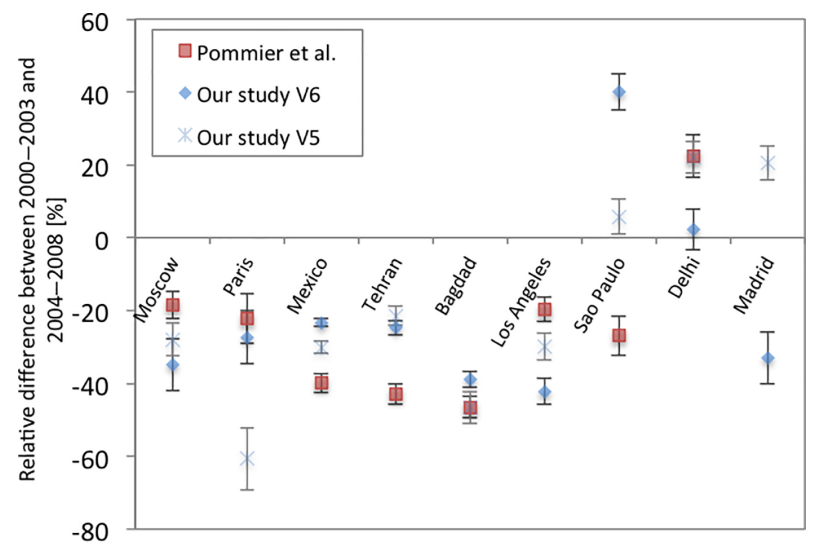

Figure 5. Calculated RDs, comparing results of the satellite-only approach from this study (diamonds for MOPITT version 6, stars for MOPITT version 5) and the study of Pommier et al. (2013; squares). The error bars represent trend uncertainties, following the calculation method that was used in P13.

\subsubsection{Simulation period}

To reduce the random noise and to increase the signal from relatively small sources, it is required to average MOPITT data over longer time periods, as in the earlier studies already mentioned (e.g., Clerbaux et al., 2008; Girach and Nair, 2014; Deeter et al., 2014). Averaging times ranged in these studies from 1 month for the second study to 7 years for the first study; it should be noted, however, that these studies used a coarser spatial resolution: $1^{\circ} \times 1^{\circ}$. In our study we chose to average 1 year of data, which resulted in quite a good comparison with WRF: $R^{2}=0.75$. This $R^{2}$ value quantifies the fraction of the variance in the MOPITT data that is explained by WRF. We also found a clearly visible enhancement of $\mathrm{CO}$ mixing ratio over the city of Madrid for this an- nual period. A description of the more detailed test we did that resulted in the use of the period of a year can be found in the Supplement.

\subsubsection{From model mixing ratios to emissions}

For comparison with MOPITT, model simulations were done for the years 2002 and 2006 with EdgarV4.2 emissions of the corresponding years. For each year also a background simulation was performed, where the boundary and initial conditions are kept the same as in the simulations with emission but where emissions were switched off. The difference between these simulations represents the contribution of the emissions of Madrid to the simulated CO concentrations.

Since tracer transport in WRF is linear, the CO contribution from Madrid scales linearly with its emission. Because of this, the optimal, i.e., best fit, emission was linked to the inventory emission by a scaling factor $\left(f_{\text {emis }}\right)$ of the simulated urban plume: the difference between $\mathrm{CO}$ in the emission and background simulation. To make this method easily applicable to other regions and to limit the required WRF computation time, we implemented only direct anthropogenic $\mathrm{CO}$ emissions and assumed a uniform distribution of other sources of $\mathrm{CO}$ (e.g., anthropogenic sources of $\mathrm{CO}$ in the surroundings, direct natural sources and indirect sources of $\mathrm{CO}$ such as the atmospheric oxidation of natural and anthropogenic volatile organic carbon compounds and methane from the city or the surrounding forests). To account for these missing sources in the $200 \times 200 \mathrm{~km}^{2}$ area around Madrid, a background correction factor $\left(f_{\text {back }}\right)$ was introduced that has no spatial pattern but is simply a multiplication factor of the concentrations in the background simulation.

After a WRF simulation, the WRF data were sampled according to the MOPITT retrievals, the AK matrix and MOPITT a priori profile were applied, and the mixing ratios were 
gridded on a $2 \times 2 \mathrm{~km}^{2}$ grid and averaged over the entire column with the oversampling technique of Fioletov et al. (2011), as described in Sect. 2.2 and used in P13. Using the total column data in molec $\mathrm{cm}^{-2}$, as done in P13, is not appropriate here, due to the effects of orography that also influence the match between the model and satellite. Instead, the column average $\mathrm{CO}$ mixing ratio was used. Note that we do not use the surface layer $\mathrm{CO}$ mixing ratio but the total column since the bias, and bias drift, of the multispectral total column product is much lower than that of one or a few layers near the surface (Deeter et al., 2014).

To estimate $\mathrm{CO}$ emissions, we used a simple optimization scheme based on Brent's method (Brent, 1973; Press et al., 1992). We minimized the difference between MOPITT and WRF average column mixing ratios by varying $f_{\text {backg }}$ and $f_{\text {emis }}$ iteratively using Brent's method. Brent's method is a root-finding algorithm, which we used to find the minimum of the quadratic cost function $J\left(\mathrm{ppb}^{2}\right)$, defined as

$\boldsymbol{J}=\sum_{i=1}^{n}\left(\left(\boldsymbol{X}_{\bmod [i]}\left(f_{\text {backg }}, f_{\mathrm{emis}}\right)-\boldsymbol{X}_{\mathrm{sat}[i]}\right)^{2}\right)$.

In this function, $n$ is the number of grid cells within the $200 \times 200 \mathrm{~km}^{2}$ optimization domain. $\boldsymbol{X}_{\bmod [i]}$ is the total column average mixing ratio (ppb) in the $i$ th grid cell of the model and $\boldsymbol{X}_{\mathrm{sat}[i]}$ the mixing ratio (ppb) in the corresponding MOPITT grid cell. We filtered out data where the difference between MOPITT and WRF was more than 3 times the standard deviation of their mean difference to prevent outliers from influencing the emission estimation. The $\boldsymbol{X}_{\text {mod }}$ is build up from data of the background simulation $\boldsymbol{X}_{\text {backg }}$ and the full simulation including emissions $\boldsymbol{X}_{\text {emis }}$ according to

$\boldsymbol{X}_{\text {mod }}=\boldsymbol{X}_{\text {backg }} \cdot f_{\text {backg }}+\left(\boldsymbol{X}_{\text {emis }}-\boldsymbol{X}_{\text {backg }}\right) \cdot f_{\text {emis }}$.

\subsubsection{Sensitivity tests}

In order to determine how sensitive our method is to different spatial averaging, different prior emissions and different filtering methods, we performed some sensitivity tests. We tested the optimization with a 10 times coarser grid, i.e., $20 \times 20 \mathrm{~km}^{2}$, to investigate the sensitivity to the chosen grid size and decrease the importance of patterns in the background and emission. We also used different prior emission patterns: for 2006 we started the optimization with TNOMACC-III emissions (Kuenen et al., 2014); for 2002 we did a test optimization starting with emissions of 2006. We also tested the sensitivity to emissions in the direct surroundings of the $200 \times 200 \mathrm{~km}^{2}$. Extra background simulations were performed in order to quantify this: simulations with emissions outside of the $200 \times 200 \mathrm{~km}^{2}$ box around Madrid, and, as the normal simulation, without emissions in the urban area where the optimization was performed.

To analyze the robustness of the method, we repeated the optimization using different data filters and investigated the effect of optimizing the absolute difference instead of the quadratic difference in Eq. (4). Four different filtering methods were tested to prevent outliers in the MOPITT data from influencing the estimation: (1) filtering out all MOPITT data that were more than three or (2) four standard deviations from the yearly $200 \times 200 \mathrm{~km}^{2}$ mean MOPITT CO concentration, or filtering out all MOPITT and WRF data at the same time and location that had a larger difference between them than (3) three (which is the default method) or (4) four standard deviations from the mean difference between MOPITT and WRF at the same time and location.

\section{Results and discussion}

\subsection{Emission trend estimation and uncertainty based on satellite data only}

The first method we used to estimate emission trends from large cities is the one applied before by P13. To estimate the uncertainty in these values, we used both version 5, as in P13, and version 6 of the MOPITT multispectral data in these calculations.

The typical downwind minus upwind MOPITT columns in our analysis - a proxy for the emission - range from $1 \times 10^{17}$ molecules $\mathrm{cm}^{-2}$ (Madrid, Delhi, Paris) up to $7 \times 10^{17}$ molecules $\mathrm{cm}^{-2}$ (Mexico City). When using MOPITT version 5 data (V5), we found some significant differences between our study and P13 (total difference range: $0.006-1.8 \times 10^{17} \mathrm{molec} \mathrm{cm}^{-2}$ ), with an average absolute discrepancy between our study and P13 of $0.5 \times$ $10^{17}$ molecules $\mathrm{cm}^{-2}$ over 2000-2003 and 2004-2008 together (Table S1 in the Supplement and Fig. 4).

The changes between the 2000-2003 and 2004-2008 periods, used to assess the trend in the emissions, are between $+0.2 \times 10^{17}$ and $-2.4 \times 10^{17}$ molecules $\mathrm{cm}^{-2}$. This results in negative trends (RDs, see Sect. 2.2) in the order of -48 to $-4 \%$ for most cities (Fig. 5) and a positive RD of $15 \%$ for Delhi and $+5 \%$ for Madrid. As we attempted to use exactly the same method as P13, with only a slight difference in the use of wind data, our results suggest that the uncertainties of the emission proxies in P13 (0.01$0.1 \times 10^{17}$ molecules $\mathrm{cm}^{-2}$ ) were underestimated. A more realistic uncertainty for the emission proxy should rather be on the order of the mean discrepancy we found, i.e., $0.5 \times 10^{17}$ molecules $\mathrm{cm}^{-2}$.

Comparisons of the MOPITT V6 data with P13, expected to give some differences due to the different retrieval algorithm of V6 compared to V5, also show rather large differences (Table S2), with an average discrepancy of $0.4 \times$ $10^{17}$ molecules $\mathrm{cm}^{-2}$. When the results of our approach are compared between using V5 and V6 of the data (compare Table S1 with Table S2), we find absolute discrepancies between $0.009 \times 10^{17}$ and $1.01 \times 10^{17}$ molecules $\mathrm{cm}^{-2}$ with an average discrepancy of $0.3 \times 10^{17}$ molec $^{-2}$. The differ- 
ences between V5 and V6 with our approach are thus smaller than the individual ones compared to P13, but still not negligible.

For Madrid, using V6, we find a negative trend of $-33 \%$ (Table S2). The magnitudes of the RDs, see Fig. 5, found in our study are clearly different from those found in P13 and in the case of Sao Paulo the RD even shows an opposite sign ( $+40 \%$ vs. $-27 \%$ in P13). Using V6, only one of our RDs was within the error range of P13 given for the RD. For V5, only two of the RD estimations were inside the error range given in P13. The RD estimations, however, do agree with an absolute uncertainty difference of $\sim 20 \%$ for most cities, so the method still has some value to make a rough estimation of trends in a simple and fast way. An explanation for the large discrepancies in RDs, while the $V_{\mathrm{d}}-V_{\mathrm{u}}$ values are relatively close, is that the absolute changes between the two periods are close to our revised uncertainty estimate, and the RDs are thus almost in the uncertainty range of the method.

Our results demonstrate that the method described in P13 gives a useful first guess of trends in emission, but also that the robustness of the method is only limited: the emission trends are small in comparison with the uncertainty in the upwind-downwind estimates and they are thus not well resolved by the method. V6 differs from V5 mainly by a correction for the geolocation bias, an updated a priori and different meteorological fields (Deeter, 2013a). In an attempt to better understand the factors limiting the robustness of the approach, we identified a number of limitations inherent in the method, partly based on the differences between MOPITT V5 and V6, which will be discussed next.

\subsection{Limitations of the satellite-only approach: possible sources of errors and sources of uncertainties}

In this section, we will analyze the possible influence of temporal variations in sampling, a priori and the averaging kernel on the estimation of multi-year average emission trends from MOPITT retrievals, which possibly give errors in the emission trend estimation. We will also look at the influence of choices to filter and rotate the data that lead to uncertainties in the trend estimation. The effects of bias drift in the MOPITT retrievals, described in the validation papers (Deeter et al., 2013, 2014), are not tested here. The influence is, however, expected to be negligible, since the total column product is used to estimate emission trends which have a drift of $0.001 \pm 0.003 \%$ per year for the V5 and $0.003 \pm 0.002 \%$ per year for the V6 multispectral product, and the drift is existent in both the upwind and the downwind $\mathrm{CO}$ column.

\subsubsection{Sampling differences and averaging period}

The a priori information that is used in the MOPITT retrievals is the same each year, but accounts for seasonal variation. Close to cities, this seasonal variation reflects both the change in emissions over the year, with higher emissions in winter and low emissions in summer, and the seasonal cycle of the $\mathrm{OH}$ sink, which varies with season and peaks in summer (e.g., Girach and Nair, 2014; Lal et al., 2000; Novelli et al., 1998), leading also to low CO mixing ratios in summer. Because of this, seasonal variations in measurement coverage may bias annual averages. For example, a year with fewer overcast days in summer than an average year - so less data filtered out - would lead to a lower annual average CO estimation compared to an average year, even if the $\mathrm{CO}$ mixing ratios were exactly the same in those years. However, uneven sampling would not affect the RD calculation as long as the background and the city signal are influenced equally. To investigate the sensitivity of the RD calculation to uneven sampling, we analyzed the a priori data for the years 2000 2008. The a priori is a good measure for this, since it is extracted from the retrieval data and therefore sampled in the same way as the retrievals.

When we averaged a priori data, annual mean a priori $\mathrm{CO}$ varied by $1 \times 10^{16}-1 \times 10^{17}$ molec $\mathrm{cm}^{-2}$ between years, which is of the same order of magnitude as the long-term trends in $\mathrm{CO}$ that are estimated with the satellite-only method (Fig. 6, left). The effect can be seen very well in the years 2000 and 2001. In 2000 there are no satellite data for the months January and February, biasing the average towards low summer columns. Oppositely, in 2001, June and July data are missing, which increases the annual mean. In the right panel of Fig. 6, the downwind minus upwind concentration differences per year are calculated for the a priori data for cities with enhanced $\mathrm{CO}$ mixing ratio over their centers in the a priori. For Baghdad, Moscow and Madrid, the 2000 $V_{\mathrm{d}}-V_{\mathrm{u}}$ is lower than that of 2001. New Delhi, with a different yearly $\mathrm{CO}$ pattern due to the monsoon, does not show this difference. In this picture, however, also all the other years show varying emission proxies of similar quantity. This suggests that the sampling problem has also a spatial dimension. The calculated RDs for the four cities based on a priori data are not $0 \%$, as expected for annually repeating priors, but $+11.8 \%$ for Madrid, $-13.3 \%$ for Baghdad, $20.6 \%$ for Moscow and $-2 \%$ for Delhi. These results indicate that temporal variations in sampling may significantly influence emissions trends obtained using the satellite-only method.

Some recent studies on CO trends over larger regions overcame the uneven sampling problem by deseasonalizing the data before studying trends (Strode et al., 2016; Girach and Nair, 2014). In our method using the WRF model (see below), the problem of uneven sampling is largely solved as we sample our model according to the availability of satellite data.

\subsubsection{Role of the a priori}

When using only satellite data to estimate emission trends, it is important to consider how satellite data are obtained: the maximum a posteriori retrieval is based on a set of measured radiances, a radiative transfer model, and a model-derived 

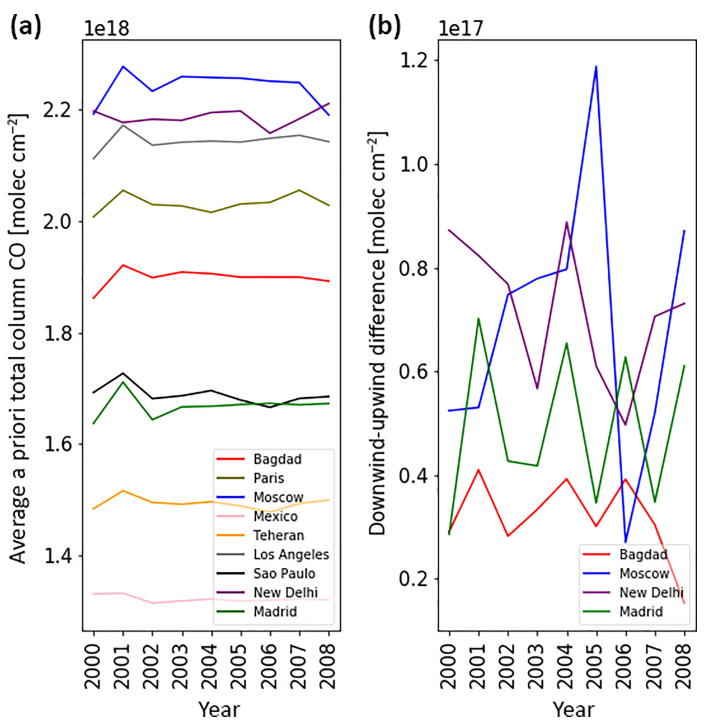

Figure 6. (a) Variations in annual mean a priori total column CO over the years due to uneven sampling. Averages were made over the $200 \times 200 \mathrm{~km}^{2}$ domain around each city. (b) Variations in annual mean downwind-upwind differences in total column a priori $\mathrm{CO}$ over the years. Only cities with a distinct city-like pattern in the a priori are shown.

a priori profile. The averaging kernel represents the weighting of the measured signal and the a priori information in the retrieved CO profile (see Sect. 2.1). The a priori information of MOPITT version 6 is based on monthly climatologies, temporally and spatially interpolated to generate a priori values for a specific location and day (Deeter et al., 2014) on a $1^{\circ} \times 1^{\circ}$ (latitude $\times$ longitude) spatial resolution. This results in a priori fields which are already quite detailed: the a priori data of the eight cities of P13 and Madrid reveal already the location of some of the large cities. The MOPITT V5 and V6 data make use of different a priori information. For all of the cities there are slightly different concentration patterns in the a priori products between these two versions. This raises the question to what extent the differences in emissions trends derived from the two MOPITT versions in Fig. 5 are explained by different a priori. To investigate this in more detail, we compared the emission estimation of the satelliteonly approach for the standard and a uniform a priori over the whole domain. From this test, however, we could only find a minor contribution of the a priori to the RD. For Madrid we find, for example, a $2 \%$ change in RD estimation when a uniform a priori was used; for Baghdad we find a $3 \%$ change; for New Delhi a $6 \%$ change and for Moscow a $2 \%$ change. The differences are, however, somewhat larger, i.e., on the order of $5 \%$, when we replace the version 6 a priori with the version 5 a priori data. This last step, however, required the use of the data that was available in both V6 and V5 of the data, leading to a decrease in the amount of data the estimations were based on. To be sure to look at the effect of the a priori only, we used the WRF model data for the years 2002 and 2006 to calculate the RD with a uniform a priori (the average MOPITT a priori) and the standard MOPITT a priori. From this test, we found a decrease in the RD of only $1.2 \%$ when the uniform a priori was used. The change in a priori thus causes around $5 \%$ change in RD estimation between version 5 and 6.

\subsubsection{Averaging kernel stability}

Since the city CO emissions take place in the lowest layers of the atmosphere, the amplitude of the retrieved city signal depends strongly on the sensitivity of the MOPITT retrieval to these altitudes; any temporal change in this sensitivity will influence the emission trend estimation. Yoon et al. (2013) already concluded that a temporal change in the AK can lead to a significant error in the trend estimation of retrieved CO. Our analysis shows that there is a change in the average multispectral AK shape over the years 2000 to 2004 over Madrid (Fig. 7). The slight shift in AK sensitivity reduces the sensitivity to the lowest layers (from surface to $800 \mathrm{hPa}$ ) and increases the sensitivity to the mid-troposphere $(300-500 \mathrm{hPa})$. After 2004, these sensitivities stabilize, except for some year-to-year variation. To show this, we used the $\mathbf{A K}$ area (Rodgers, 2000): for each vertical layer the sum of all values of the corresponding row in the AK matrix, averaged over the years for all months with data in all years of our sample period (i.e., March-December, except June and July); note that the figures are very similar to the figures where all available months are taken for each year (not shown). We found downward trends near the surface of $-16 \pm 6 \%$, and upward trends at $400 \mathrm{hPa}$ of $+8 \pm 3 \%$ over the years 2000 2004 (Fig. 7, right panel). In Fig. 7 we show this effect for Madrid, but it is visible for all cities analyzed in P13. This sensitivity change might have been caused by instrument degradation, variability in meteorological conditions and/or changes in the $\mathrm{CO}$ abundance over the years (Strode et al., 2016). The NIR data show a decreasing sensitivity over all layers in time. The increasing sensitivity to the layers higher up comes from the TIR data (Fig. S1, Supplement).

The AK trends may not be large but the city CO signal compared to background is not large either. As the CO concentration gradient around sources is largest in the layers near the surface, and lower higher up, the trend in the $\mathbf{A K}$ causes an artificial negative trend in the concentration enhancement over cities, biasing the emission trends derived from the satellite-only method. For Madrid, we tested this by constructing a synthetic data set of MOPITT retrievals for the years 2000 to 2008, all based on WRF-Chem simulated CO vertical profiles over Madrid for 2002 sampled at MOPITT time and location. For each year, we constructed artificial AKs based on the MOPITT AKs. Every AK is scaled such that the annual mean sensitivity remains at the level of 2002 for each AK layer. This led to a negative difference in $\mathrm{RD}$ of $-5 \%$ compared to the same calculation with origi- 

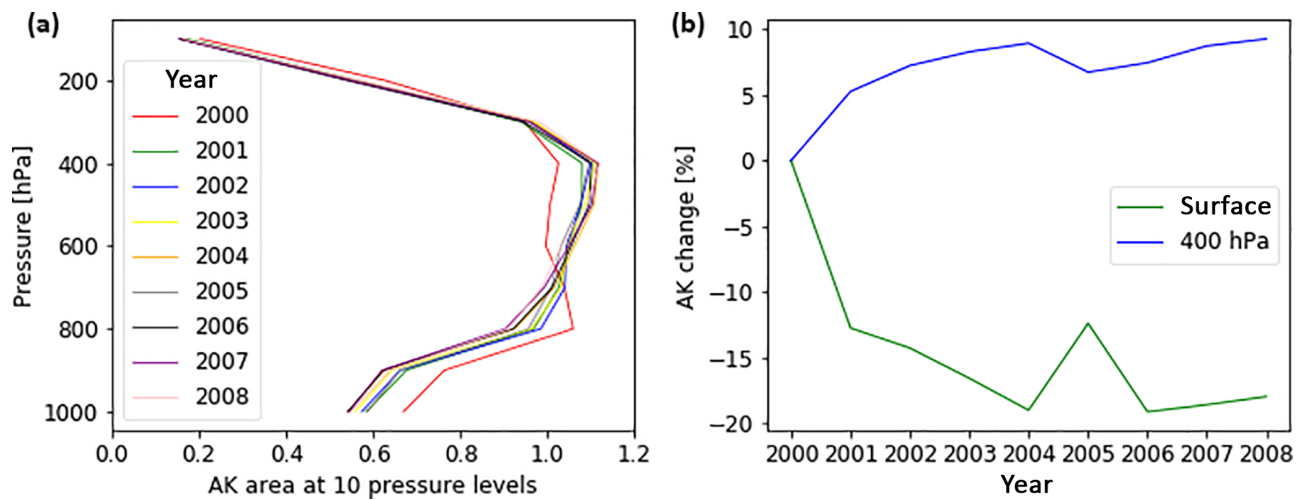

Figure 7. Yearly averaged AK area (Rodgers, 2000) values over the $400 \mathrm{~km}^{2}$ area around Madrid for the years 2000 to 2008 , MarchDecember (except for June and July to minimize biases from uneven sampling), for the V6 multispectral product: (a) vertical profiles from the surface to the top level for corresponding main diagonal value of the $\mathbf{A K}$, (b) change in average AK compared to the year 2000 for the surface level (blue) and $400 \mathrm{hPa}$ level (green).

nal AKs. From this result, we conclude that the stability of the $\mathbf{A K}$ is influencing the emission trend estimation using the satellite-only method, which introduces an uncertainty when using satellite data from MOPITT and potentially also other instruments. It should be noted, however, that the averaging kernel is quite specific for each retrieval and replacing it by a corrected $\mathbf{A K}$, as done here, is justified as a sensitivity test but is not considered a solution to the problem, as indicated by the data description paper published in Deeter (2002).

\subsubsection{The rotation point selection}

In the satellite-only approach, a wind rotation technique is applied to calculate upwind-downwind differences. This technique selects a single point in the center of the city as rotation point. However, we found that the estimated upwinddownwind differences are sensitive to the location of this rotation point, which is problematic since it is hard to tell what the exact center of a city is. Moving this rotation point for example from the center defined by Wikipedia to the center point defined by Google Maps (GM), which differs by $0.7-$ $3.9 \mathrm{~km}$ for our selected cities (both locations could be equally well defined as center), gives downwind-upwind differences varying by $0.03 \times 10^{17}-0.3 \times 10^{17}$ molec cm $^{-2}$, corresponding to RDs varying by $8-25 \%$ (Fig. 8). As a solution to this problem, using the weighted emission center of the city instead of the general center would be a fairer way to apply this method. We tested this for the city of Madrid for the weighted center point in the TNO-MACC-III emission inventory and weighted center point of the EdgarV4.2 emission inventory. We found a positive RD of $+3 \%$ for the Edgar center and a negative RD of $-4 \%$ for the MACC center, which was located $8 \mathrm{~km}$ further south. These last estimations are probably better estimations of the real trend, since they use the center of the emissions instead of the center of the buildings, but this problem is difficult to solve, since the exact center of emissions is also not known.

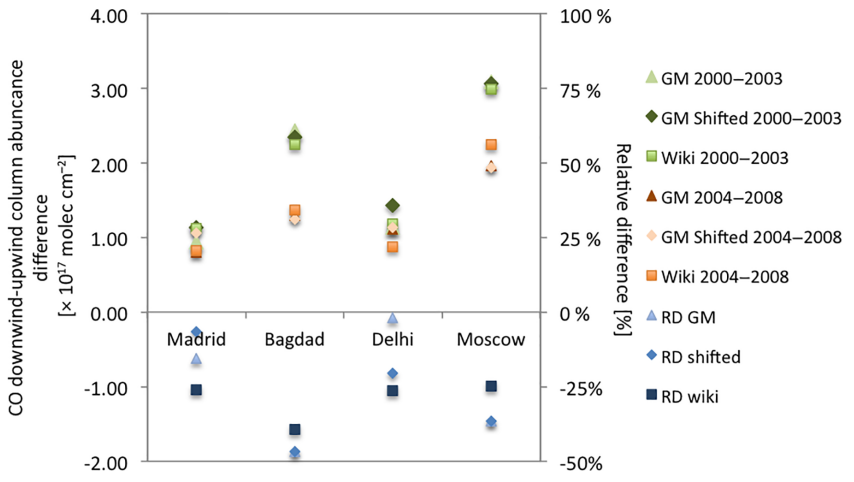

Figure 8. Upwind-downwind difference (left axis, orange, green) and RD calculation (right axis, blue points) for Madrid, Baghdad, Delhi and Moscow using different rotation points within the city center. GM: Google Maps location of the center; GM shifted: $5 \mathrm{~km}$ shift of this point to another center location; Wiki: Wikipedia location of the center. Wikipedia center points are off by 3.9, 3.1, 2.1 and $0.7 \mathrm{~km}$ from the GM center points for Madrid, Baghdad, Delhi and Moscow, respectively.

The satellite-only method is thus highly sensitive to the selected location of the rotation point, which introduces a large uncertainty in the estimated emission trends. This outcome is particularly relevant for the use of MOPITT data, because of a location bias in MOPITT version 5, which has been corrected in version 6 . This can be an important reason for the differences in emission trends found between V5 and V6. We note that the geolocation bias correction that was used in P13 and our study was slightly different from the correction done for V6 of the data by the MOPITT team (Deeter, 2012). This is a potential source of error, since small location shifts can have a substantial effect on the RD estimation. 

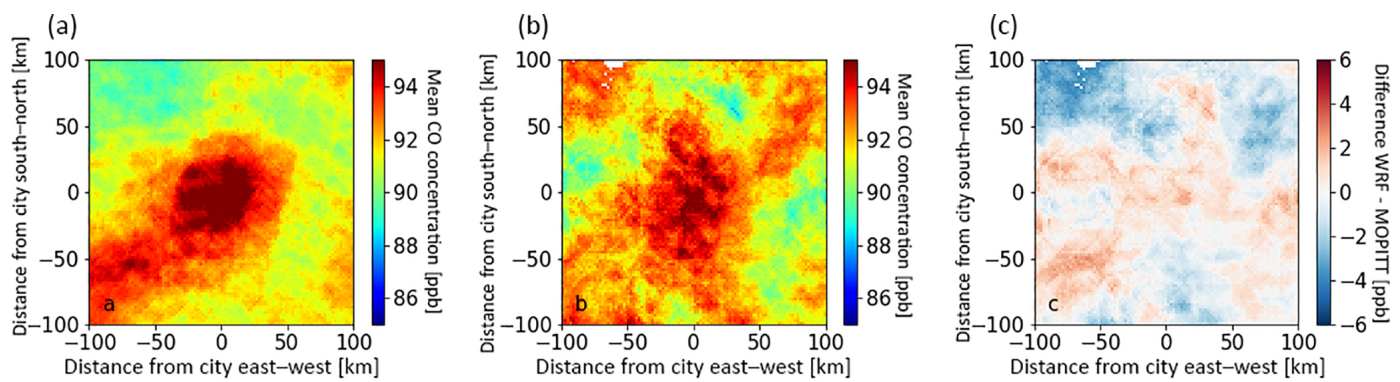

Figure 9. Column average mixing ratios of $\mathrm{CO}$ for 2002 before and after emission optimization in WRF: (a) only background optimization, (b) MOPITT V6 signal, (c) difference WRF-MOPITT after background optimization, (d) WRF after background and emission optimization. (e) As (b). (f) As (c) but now after background and emission optimization. The optimal emission is found to be 0.52 times the original emission.

\subsubsection{Other sources of uncertainties}

Since we used a slightly different pressure level for the top of the boundary layer (BL) than P13 to calculate the average wind direction, we tested the sensitivity of the RD calculation to the height over which the wind direction was averaged. For this test we took the average over 12 (low BL), 15 (normal BL) or 18 (high BL) hybrid pressure layers, respectively, at an average pressure of 808,717 and $613 \mathrm{hPa}$. The height of the averaging was found to be quite important in determining the value of the RD. For some cities, the differences were rather small, but for Moscow, Paris, Sao Paulo and Delhi, significant differences were found between the RD values for the calculations using different pressure layers. We found absolute differences of over $20 \%$, and an opposite trend sign for Delhi, where the downwind-upwind difference between the two periods is rather small. Just as was found for the dependence on the location of the rotation point, the downwind-upwind emission estimation values are usually quite close to each other, but the difference between 2000-2003 and 2004-2008 is relatively small compared to the spread in downwind-upwind values of one period, leading to large differences in the RD values, as P13 also described in the supporting information of the paper. From this we conclude that the choice of the height over which the wind direction is averaged is important for the satellite-only technique. Since there is no objective criterion to choose the "best" height for rotating the $\mathrm{CO}$ column values, this introduces another systematic source of error that will affect the reliability of the results. By extending the cloud filtering from data with less than $5 \%$ clouds, as we did by filtering on cloud diagnostic 1 or 2 , to data with a maximum of $0 \%$ clouds, as in P13, the amount of data is reduced by less than $1 \%$. The emission estimation, however, still changes for some cities. For Paris, the downwind-upwind difference is changing by $27 \%$ for the 2004-2008 period. The absolute RD change is around $6 \%$ for most cities, although for Delhi a $21 \%$ difference was found. We do not filter MOPITT data for retrievals containing water bodies other than rejecting water and mixed retrievals using the standard MOPITT flags. Since MOPITT is not able to measure $\mathrm{CO}$ in the near-infrared over areas with low albedo, such as water, this can lead to biases in the emission trend estimates in our method. For Los Angeles and Sao Paulo, which are both close to the coast, our analysis may include some scenes with fractional areas of water, while P13 filtered these out. This might explain part of the difference in RD estimation seen in Fig. 5, especially for Sao Paulo. As described in the supporting information of P13, also the averaging radius, the size of the grid cells and the across-wind averaging distance can significantly influence the RD estimation.

\subsection{WRF optimization method}

To overcome the limitations of the satellite-only approach and to be able to quantify emissions, we developed a different method using the WRF model in addition to the satellite data. For this method, the model is sampled at the location and time of each individual satellite measurement. Since the model accounts for the seasonality in $\mathrm{CO}$, the model and satellite data are influenced in the same way by uneven seasonal sampling. Therefore, its influence on the derived trend is expected to cancel out. The model optimization approach does not need wind rotation, avoiding the uncertainties introduced by this procedure. Likewise, any variation or trend in the $\mathbf{A K}$ influences the model in the same way as it does with the measurements. In addition, the model accounts for influences of varying meteorological conditions on the dispersion of the city plume. Besides these advantages of using WRF, there is one notable drawback, which is the computational cost of a simulation covering several years. As explained in the Sect. 2, we do simulations of 1 year; the accompanying $R^{2}$ between the gridded oversampled WRF and MOPITT is then 0.75 .

Emissions were estimated by minimizing the cost function as described in Sect. 2.3.6. In all simulations, the modelled $\mathrm{CO}$ columns were smaller over the whole domain compared to the satellite, probably due to the omission of secondary and natural $\mathrm{CO}$ sources (e.g., from oxidation of naturally 
emitted hydrocarbons) in the model. Over larger geographical regions, biogenic sources can contribute 40-80\% of the CO column (Choi et al., 2010; Hudman et al., 2008). As explained, we therefore optimize both the background and the anthropogenic emissions by two scaling factors, taking into account the AK in the comparison between MOPITT and the WRF data.

\subsubsection{Emission estimation based on the WRF optimization method}

We performed emission optimizations for the years 2002 and 2006. Starting with the initial emissions for each associated year from EdgarV4.2, we find an optimum of $52 \%$ of the EdgarV4.2 emissions in 2002 and $83 \%$ of the estimated EdgarV4.2 emissions in 2006. This allows us to directly estimate emissions for Madrid for these years: averaged over the $200 \times 200 \mathrm{~km}^{2}$ domain the corresponding emission is $0.22 \mathrm{Tg}$ of CO for 2002 and $0.20 \mathrm{Tg}$ of CO for 2006. Figures 9 and 10 show the column-averaged mixing ratio patterns before and after optimizing the emission, in comparison with the MOPITT signal and the remaining difference between WRF and MOPITT.

Differences within the emission inventories of this magnitude are very possible: the EMEP/EEA air pollution guide, also referenced in the articles describing the TNO-MACC emission data set, reports uncertainties for $\mathrm{CO}$ emissions in the range of 50 to $200 \%$ for the sources that are most important in cities, such as (road) transport and commercial, institutional and residential combustion.

Figure 9 shows for the years 2002 and 2006 the offset between the model and the satellite data before and after applying the background and emission optimization. The initial misfits are in the range of 0 to $-8 \mathrm{ppb}$ (about $4 \%$ relative to the mean $\mathrm{CO}$ column mixing ratio around Madrid of $\sim 90 \mathrm{ppb}$ ). The model gives initially lower concentrations than the satellite, which is accounted for in the optimization of the background.

\subsubsection{Sensitivity tests}

It must be noted, however, that our method is quite sensitive to specific settings used in the inversion. To further investigate the robustness of the WRF optimization method a series of experiments have been performed, varying the data filtering method (Sect. 2.3.6) and the a priori emissions (using EdgarV4.2, TNO-MACC-II and TNO-MACC-III). The results of these tests are summarized in Fig. 12 and Table 1. The results of the default procedure that are shown as blue triangles in Fig. 13 are italic in Table 1. When we average the results of all tests, the average optimum is $45 \%$ of the original emission for 2002 and $87 \%$ of the original emission for 2006 (Fig. 13, upper panel). This is quite close to the estimates from the standard method, although the range of possible emissions indicates a sizeable uncertainty: for 2002, the emissions range between 0.15 and $0.24 \mathrm{Tg}$ of $\mathrm{CO}$ over the $200 \times 200 \mathrm{~km}^{2}$ area around the city center of Madrid, for 2006 this range is between 0.19 and 0.26 (with one outlier of 0.32 ) $\mathrm{Tg} \mathrm{CO}$, an uncertainty of $23 \%$ on the average value. Including the TNO-MACC (versions 2 and 3, for the year 2006) inventories as alternative emission patterns, the upper part of the range increased to $0.44 \mathrm{Tg}$ for 2006 (Fig. 13, lower panel), based on the new average value - this is an uncertainty of $56 \%$. The large sensitivity to the a priori emission pattern can be explained by the use of a single scaling factor to optimize the city emissions. Therefore, uncertainties in the emission inventory pattern, for example due to missing sources, are difficult to correct for, using our current inverse modelling setup. This was found to be a more general problem in inversion studies (Jacob et al., 2016).

To investigate the importance of the background and emission pattern, we performed an additional optimization in which we reduced the spatial resolution by averaging the retrievals and model data to a $20 \times 20 \mathrm{~km}^{2}$ grid (instead of $2 \times 2 \mathrm{~km}^{2}$ ) in the domain around Madrid. Using this approach, we find reduced optimal emissions, with differences up to $20 \%$ (Table 1 , optimization method: $20 \times 20$ ).

Sensitivity to the prior emission pattern has been investigated in further detail by (1) changing WRF's background emissions, (2) inspecting the differences when using a different emission pattern by using both TNO-MACC and EdgarV4.2 emissions as priori in the model for 2006, (3) using the EdgarV4.2 2006 emissions as prior in the model for 2002 and (4) using TIR instead of the multispectral MOPITT data to do the optimization. The results have been analyzed by examining the impact on the shape of the cost function (Fig. 12). While the value of the cost function at the minimum quantifies how well the data are fitted, the second derivative of the cost function quantifies the robustness of the emission estimate. For all the 2006 optimizations the second derivative of the cost function is lower, i.e., is less steep than for the standard optimization for 2002, indicating that the uncertainty of the estimated emissions is smaller for 2002 than for 2006. The effect of the different sensitivity tests on the cost function is described below.

To investigate the contribution of emissions outside the optimization area on the pattern in $\mathrm{CO}$ in the optimization area, we performed a sensitivity test (sensitivity 1), replacing the normal background simulation, without any emissions, with a background simulation that has emissions in the area outside the $200 \times 200 \mathrm{~km}^{2}$ optimization area. In the ideal case these "background emissions", i.e., the emissions within the WRF domains around the optimization area, only contribute to the background of the $200 \times 200 \mathrm{~km}^{2}$ area around Madrid without affecting the city pattern. In this case, it is sufficient to optimize the background with only one factor. If the emissions do contribute to the pattern, we expect the results to have lower cost function values in the optimum. The impact on the optimized emission of Madrid was, however, well within the estimation uncertainty, as can be seen in Fig. 12 

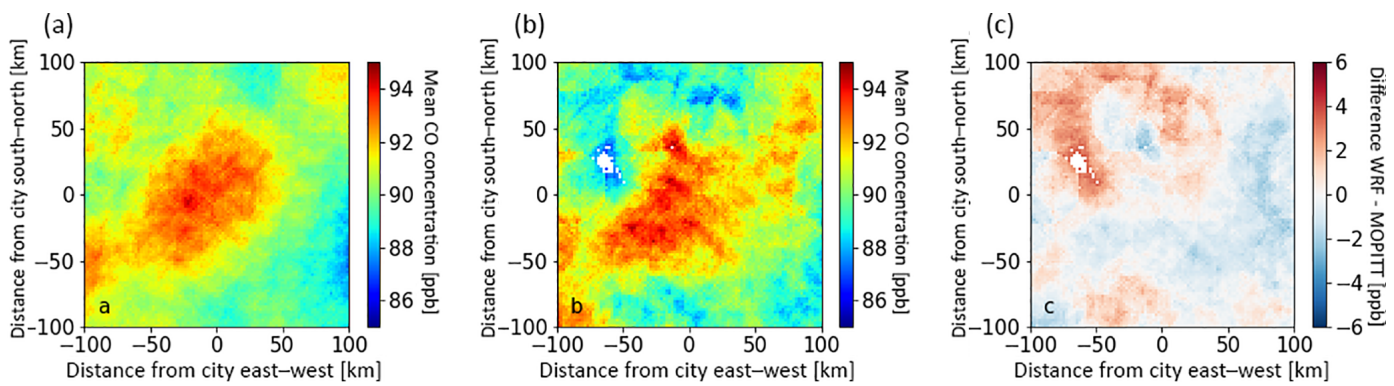

Figure 10. As Fig. 6 for 2006: (a) only background optimization, (b) MOPITT V6 signal, (c) difference WRF-MOPITT after background optimization, (d) WRF after background and emission optimization. (e) As (b). (f) As (c) but now after background and emission optimization. The optimum emission is found to be 0.83 times the original emission.
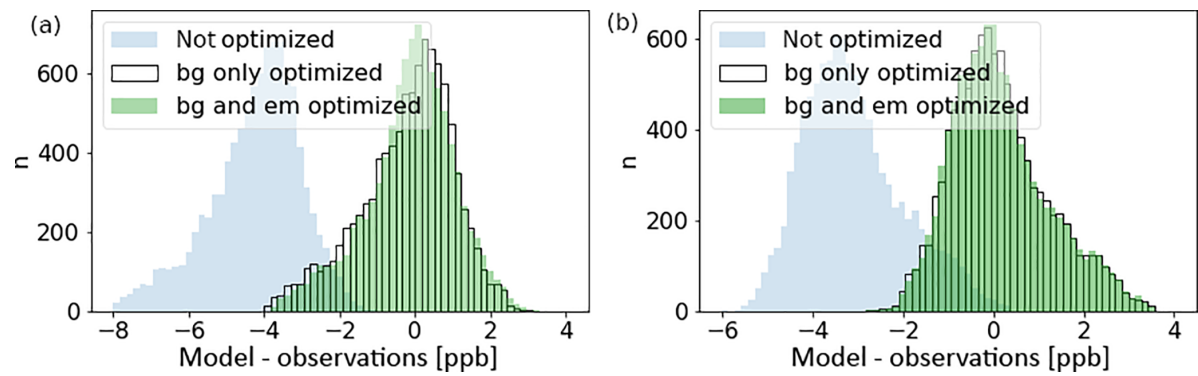

Figure 11. Comparison of prior and posterior misfits of the WRF model to the MOPITT retrievals: (a) year 2002, (b) year 2006. Blue bars depict the difference between the model and satellite data before optimization, white bars the difference after background optimization and green bars the difference after background and emission optimization.

from the difference between solid and dotted lines. These show that the differences between the cost function values with and without accounting for these emissions are negligible. The emission estimates, however, with this replaced background, are, especially for 2002, consistently lower than with the standard background - on average $16 \%$ for 2002 and $1 \%$ for 2006.

Emission patterns differ between the TNO-MACC and the Edgar inventories (sensitivity 2). The cost function minimum was slightly lower for the simulation with the TNO-MACCIII inventory compared to the simulation that uses Edgar emissions. The TNO-MACC-III simulation, however, also produces a minimum that is clearly less confined and therefore less robust.

For 2002, implementing 2002 emissions clearly gave better results than implementing 2006 emissions (sensitivity 3, not shown). In the end, the most reliable results for 2002 and 2006 were obtained using EdgarV4.2 emissions in combination with multispectral data.

The cost function of the TIR optimization (sensitivity 4) is as steep as that of the standard multispectral optimization, but the cost function values are much higher in the minimum, indicating that the TIR data are more difficult to fit by scaling the emissions in WRF. This can be explained by emissions outside the $200 \times 200 \mathrm{~km}^{2}$ region having a relatively strong influence on the $\mathrm{CO}$ mixing ratios at altitudes where the TIR retrievals are most sensitive.

Despite the various influences on the accuracy of the WRF optimization discussed in this section, the uncertainties in the estimates, $23 \%$ for 2002 and up to $56 \%$ for 2006, are still smaller than the reported uncertainties in the emission inventories of $50-200 \%$. This confirms that estimating city CO emissions using MOPITT and WRF seems feasible. However, the current noise in MOPITT data required averaging over at least yearly time periods before there was a clearly distinguishable signal of Madrid. Next to this, further improvements in the methodology are needed to decrease the uncertainty, such as the improved treatment of the background concentration.

\subsubsection{Limitations of the WRF optimization method}

As we found in the sensitivity tests, an important source of uncertainty is the background optimization. As can be seen in the images in the rightmost columns of Figs. 9 and 10, considerable differences between MOPITT and WRF remain in the background column mean mixing ratios after optimization. Optimizing the background with a single scaling factor for the whole domain is clearly insufficient to account for the complex pattern of differences between the model and the satellite. Part of the pattern is probably still related to noise in the MOPITT data, since we did not filter for very low or 


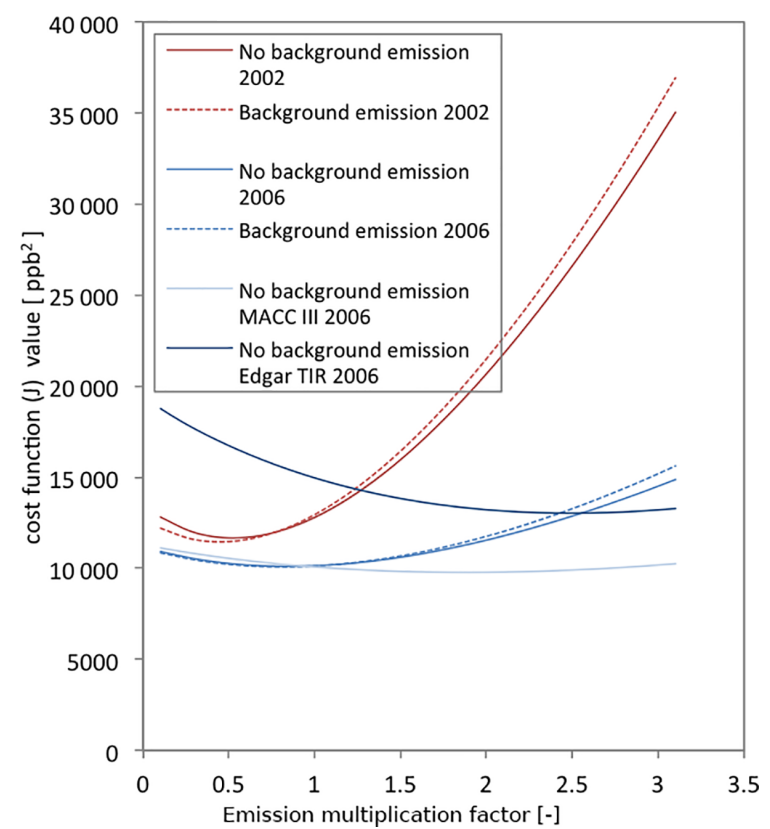

Figure 12. Comparison of the cost functions of WRF inversions using Edgar for the year 2002 (red), 2006 (blue), TNO-MACC-III for 2006 (light blue). Dark blue: inversion using Edgar and MOPITT V6 TIR data instead of multispectral for 2006. Dotted lines: emissions outside the $200 \times 200 \mathrm{~km}^{2}$ area are accounted for in the background run. Solid lines: no emissions outside the $200 \times 200 \mathrm{~km}^{2}$ area in the background run. Note that for the MACC run the initial emission is lower than for the Edgar run, so the multiplication factor does not give an indication of the quantitative difference in optimal emission.

high values in MOPITT, although they can have an important effect on several cells with the oversampling technique.

Another possible explanation for the remaining differences between the modelled and observed patterns might be other sources of $\mathrm{CO}$, which are not (yet) included in the WRF model, such as the atmospheric oxidation of volatile organic carbon compounds from the city or the surrounding forests. Some forested areas in the north of Madrid indeed appear to be blue on the difference maps of both 2002 and 2006, pointing to underestimated concentrations in the model compared to MOPITT, suggesting that emissions of short-lived biogenic volatile organic carbon (VOC, quickly converted to $\mathrm{CO})$ emitted from forests might play a role.

It should also be noted that we did not test for errors in WRF in the representation of the dilution and advection apart from the comparison we made with local ground measurements (Sect. 2.3.4).

\subsubsection{Trend estimation with the WRF optimization method}

To infer the trend in $\mathrm{CO}$ emissions from Madrid using the WRF optimization method, emissions were optimized for two different years: 2002 and 2006. Because of the 3 years in between and the limited inter-annual variability, it is possible to estimate the trend in emissions over Madrid in this period. Both the EdgarV4.2 and the TNO-MACC-III emission inventories report downward trends in the emissions over Madrid, with EdgarV4.2 showing the largest decrease (-46 and $-25 \%$ for, respectively, EdgarV4.2 and TNO-MACCIII between 2002 and 2006 over Madrid). With our emission optimization approach, however, we found a trend of only $-8 \%$. Averaged over all sensitivity tests, we even found an upward trend of about $8 \%$ (Fig. 13, upper panel). When the TNO-MACC II or III emissions were used to simulate the city plume we find a $35 \%$ increase in emission between 2002 and 2006 (Fig. 13, lower panel).

In the satellite-only approach, as mentioned earlier, we find for V6 a decrease of $33 \%$ between the 2000-2003 and 2004-2008 periods over Madrid. However, when we limit this satellite-only analysis to the years 2002 and 2006, a $5 \%$ emission increase is found $\left(V_{\mathrm{d}} V_{\mathrm{u}}=1.014 \times 10^{17}\right.$ in 2002 and $1.07 \times 10^{17}$ in 2006), which is in better agreement with the small increase estimated with the average of all sensitivity tests of the WRF optimization method and the relatively small decrease estimated with the standard WRF optimization method.

In all cases, the emission estimation and trend seem to be lower and less negative than emission and trend reported by EdgarV4.2 over Madrid and more similar to the TNOMACC-III inventory.

\section{Summary and conclusions}

We have developed a new method to quantify $\mathrm{CO}$ emissions of cities based on a combination of satellite data and model simulations. This method is an extension of the method developed by Pommier et al. (2013), based on the pixel averaging technique of Fioletov et al. (2011) to oversample satellite data, enabling the city signals to be distinguished within a reasonable time frame. We extended the urbanscale emission trend estimation techniques by adding $\mathrm{CO}$ mole fractions modelled with the WRF model. The comparison of model and satellite data enabled us to quantify the CO emissions over Madrid, whereas the satellite-only method was only able to determine a trend in the emissions. We identified and discussed limitations of the satelliteonly technique: it is influenced by sampling differences between years, it is slightly dependent on the a priori information used in the MOPITT retrievals (RD changes $\sim 3-$ $5 \%$ ), it is influenced by a trend in the averaging kernel (RD changes $5 \%$ ), it is strongly dependent on the exact location of the wind-rotation (RD changes up to $25 \%$ for locations up to $5 \mathrm{~km}$ apart) and some uncertainty can also come from the chosen height for wind averaging for the rotation (RD changes up to $22 \%$ ) and the chosen cloud filter method (RD changes of around 6 but $21 \%$ for Delhi). Our results suggest that the uncertainties of the emission proxies 
Table 1. Optimization-derived CO emissions comparing different approaches. The results of the default filtering procedure (shown as blue triangles in Fig. 13) are printed in italic.

\begin{tabular}{|c|c|c|c|c|c|}
\hline Emission inventory & Background run & $\begin{array}{l}\text { Optimization } \\
\text { method }\end{array}$ & & $\begin{array}{r}2002 \text { emission } \\
\left(\mathrm{kg} \mathrm{yr}^{-1}\right)\end{array}$ & $\begin{array}{r}2006 \text { emission } \\
\left(\mathrm{kg} \mathrm{yr}^{-1}\right)\end{array}$ \\
\hline \multirow[t]{9}{*}{ Edgar emissions } & \multirow{9}{*}{$\begin{array}{l}\text { No anthropogenic emissions } \\
\text { outside } 200 \times 200 \mathrm{~km}^{2}\end{array}$} & \multirow[t]{2}{*}{$\operatorname{abs}(y 1-y 2)$} & No filter & $2.31 \mathrm{E}+08$ & $1.97 \mathrm{E}+08$ \\
\hline & & & Filter $>3$ SD WRF-MOPITT & $2.31 \mathrm{E}+08$ & $1.98 \mathrm{E}+08$ \\
\hline & & \multirow[t]{5}{*}{$(y-y 2)^{2}$} & No filter & $2.00 \mathrm{E}+08$ & $1.97 \mathrm{E}+08$ \\
\hline & & & Filter $>3$ SD WRF-MOPITT & $2.02 \mathrm{E}+08$ & $1.99 \mathrm{E}+08$ \\
\hline & & & Filter $>3 S D$ squared & $2.15 E+08$ & $1.97 E+08$ \\
\hline & & & Filter MOITT $>4 \times$ SD outliers & $2.00 \mathrm{E}+08$ & $2.57 \mathrm{E}+08$ \\
\hline & & & Filter MOPITT $>3 \times$ SD outliers & $2.40 \mathrm{E}+08$ & $2.34 \mathrm{E}+08$ \\
\hline & & \multirow[t]{2}{*}{$20 \times 20$} & No filter & $1.95 \mathrm{E}+08$ & $2.02 \mathrm{E}+08$ \\
\hline & & & Filter $>3$ SD WRF-MOPITT & $1.95 \mathrm{E}+08$ & $2.03 \mathrm{E}+08$ \\
\hline \multirow[t]{9}{*}{ Edgar emissions } & \multirow{9}{*}{$\begin{array}{l}\text { Anthropogenic emissions } \\
\text { outside } 200 \times 200 \mathrm{~km}^{2}\end{array}$} & \multirow[t]{2}{*}{$\operatorname{abs}(y 1-y 2)$} & No filter & $2.17 \mathrm{E}+08$ & $1.92 \mathrm{E}+08$ \\
\hline & & & Filter $>3$ SD WRF-MOPITT & $2.16 \mathrm{E}+08$ & $1.93 \mathrm{E}+08$ \\
\hline & & \multirow[t]{5}{*}{$(y 1-y 2)^{2}$} & No filter & $1.58 \mathrm{E}+08$ & $1.90 \mathrm{E}+08$ \\
\hline & & & Filter $>3$ SD WRF-MOPITT & $1.62 \mathrm{E}+08$ & $1.91 \mathrm{E}+08$ \\
\hline & & & Filter $>3$ SD squared & $1.84 \mathrm{E}+08$ & $1.90 \mathrm{E}+08$ \\
\hline & & & Filter MOITT $>4 \times$ SD outliers & $1.58 \mathrm{E}+08$ & $2.46 \mathrm{E}+08$ \\
\hline & & & Filter MOPITT $>3 \times$ SD outliers & $1.93 \mathrm{E}+08$ & $3.19 \mathrm{E}+08$ \\
\hline & & \multirow{2}{*}{$20 \times 20$} & No filter & $1.55 \mathrm{E}+08$ & $1.91 \mathrm{E}+08$ \\
\hline & & & Filter $>3$ SD WRF-MOPITT & $1.56 \mathrm{E}+08$ & $1.92 \mathrm{E}+08$ \\
\hline \multirow[t]{9}{*}{ MACCv3 emissions } & \multirow{9}{*}{$\begin{array}{l}\text { No anthropogenic emissions } \\
\text { outside } 200 \times 200 \mathrm{~km}^{2}\end{array}$} & \multirow[t]{2}{*}{$\operatorname{abs}(y 1-y 2)$} & No filter & & $3.59 \mathrm{E}+08$ \\
\hline & & & Filter $>3$ SD WRF-MOPITT & & $3.58 \mathrm{E}+08$ \\
\hline & & \multirow[t]{5}{*}{$(y 1-y 2)^{2}$} & No filter & & $3.75 \mathrm{E}+08$ \\
\hline & & & Filter $>3$ SD WRF-MOPITT & & $3.74 \mathrm{E}+08$ \\
\hline & & & Filter $>3$ SD squared & & $3.68 \mathrm{E}+08$ \\
\hline & & & Filter MOPITT $>4 \times$ SD outliers & & $4.43 \mathrm{E}+08$ \\
\hline & & & Filter MOPITT $>3 \times$ SD outliers & & $4.24 \mathrm{E}+08$ \\
\hline & & \multirow[t]{2}{*}{$20 \times 20$} & No filter & & $3.89 \mathrm{E}+08$ \\
\hline & & & Filter $>3$ SD WRF-MOPITT & & $3.89 \mathrm{E}+08$ \\
\hline \multirow[t]{9}{*}{ MACCv2 emissions } & \multirow{9}{*}{$\begin{array}{l}\text { No anthropogenic emissions } \\
\text { outside } 200 \times 200 \mathrm{~km}^{2}\end{array}$} & \multirow[t]{2}{*}{$\operatorname{abs}(y 1-y 2)$} & No filter & & $2.89 \mathrm{E}+08$ \\
\hline & & & Filter $>3$ SD WRF-MOPITT & & $2.87 \mathrm{E}+08$ \\
\hline & & \multirow[t]{5}{*}{$(y 1-y 2)^{2}$} & No filter & & $3.23 \mathrm{E}+08$ \\
\hline & & & Filter $>3$ SD WRF-MOPITT & & $3.23 \mathrm{E}+08$ \\
\hline & & & Filter $>3$ SD squared & & $3.17 \mathrm{E}+08$ \\
\hline & & & Filter MOPITT $>4 \times$ SD outliers & & $3.64 \mathrm{E}+08$ \\
\hline & & & Filter MOPITT $>3 \times$ SD outliers & & $3.84 \mathrm{E}+08$ \\
\hline & & \multirow[t]{2}{*}{$20 \times 20$} & No filter & & $3.32 \mathrm{E}+08$ \\
\hline & & & Filter $>3$ SD WRF-MOPITT & & $3.32 \mathrm{E}+08$ \\
\hline
\end{tabular}

in P13 $\left(0.01-0.1 \times 10^{17}\right.$ molecules $\left.\mathrm{cm}^{-2}\right)$ are too optimistic. A more realistic uncertainty for the emission proxy should rather be on the order of the mean discrepancy that we found between our results for V5 of the MOPITT data and P13, i.e., $0.5 \times 10^{17}$ molecules $\mathrm{cm}^{-2}$. The absolute changes between the two periods in emission proxy are close to our revised uncertainty estimate. This leads to RDs that are very often in the uncertainty range of the method.

Some effort can be made to overcome the largest part of these problems, by, e.g., deseasonalizing the data, accounting for the change in $\mathbf{A K}$ and using the emission inventory center for wind rotation of the data. This will probably increase the reliability and robustness of the satellite-only trend estimation. We chose, however, to investigate another method, which also enabled us to quantify the emissions. With this method, we do not suffer from the limitations of the satelliteonly approach, as in our approach the model data are sampled according to the satellite data and no wind rotation is required because the model accounts for influences of varying meteorological conditions on the dispersion of the city plume. For the WRF-optimization method, it is necessary to average 1 year of data to sufficiently reduce the noise in the MOPITT retrievals to observe a clear signal from the city of Madrid. Averaging over a year will also smooth both the MOPITT and WRF data and reduce the effect of random model errors, while still providing a shorter period compared to the 4and 5-year periods used in P13. To estimate the emissions, a quadratic cost function of the difference between the satel- 

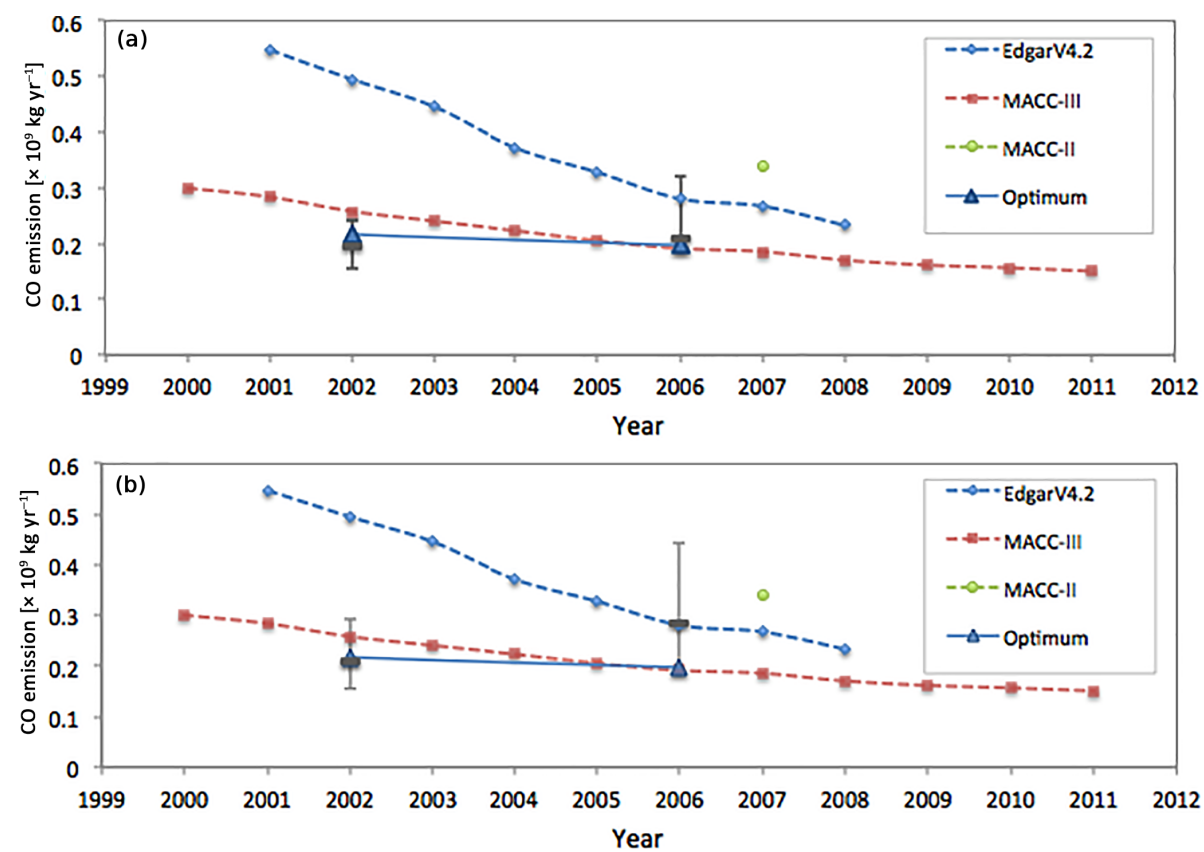

Figure 13. CO emissions in totals per year for the $200 \times 200 \mathrm{~km}^{2}$ area around Madrid, comparing inversion and inventory estimates. Blue triangles, solid line: inversion results for the year 2002 and 2006; blue dotted: EdgarV4.2; green: TNO-MACC-II; red dotted: TNO-MACCIII. The grey error bars and thick grey bar represent the range and the mean of the solutions obtained in various sensitivity tests (see text): (a) emission estimations based on EdgarV4.2 prior only; (b) including other prior emissions in the WRF model for optimization (see text). The uncertainty of the Edgar and MACC emission inventory estimates are estimated at 50-200\% (Kuenen et al., 2014).

lite and model data was minimized by adapting the emissions in the model. The optimum was found using Brent's method scaling two factors. To account for missing sources, we optimized the background concentrations with a single scaling factor over the whole area. The emission estimation is based on the change in emission factor.

For 2002 we found that at the optimum the emissions were 0.52 times the original emissions in Edgar. For 2006 we estimated the emissions to be 0.83 times the reported emissions in Edgar. These values are more in agreement with the TNOMACC-III inventory values for emissions around Madrid. After optimization, however, the remaining differences between WRF and MOPITT are still large. This is probably caused by differences in the $\mathrm{CO}$ patterns between MOPITT and WRF, especially for 2006. Additional data filtering to reduce this error or the use of other a priori emission patterns influences the optimized emissions significantly. For 2002 we found a possible range of emissions between 0.15 and $0.24 \mathrm{Tg}$ of CO over the $200 \times 200 \mathrm{~km}^{2}$ area around the city center of Madrid. For 2006 the estimations range between 0.19 and 0.26 (with one outlier of 0.32) Tg CO. Expressed as a percentage, this is an uncertainty of $23 \%$ in the 2002 emission and up to $56 \%$ for the 2006 emission. These values are still smaller than the reported uncertainties in the used emission inventories of 50-200\% (Kuenen et al., 2014). These uncertainties are comparable to our estimated uncertainty in the satellite-only method, but we also note that this new method is able to quantify emissions and that the uncertainties are based on 1-year average MOPITT and model data, instead of the 4- and 5-year averages which were used in the satellite-only method. Our relatively simple method can thus be used to make an (approximate) estimation of city emissions. Our study confirms that estimating city $\mathrm{CO}$ emissions using MOPITT and WRF is feasible. However, further development of the method is needed to improve precision and robustness.

Data availability. MOPITT V5 and V6 NIR, TIR and multispectral level 2 data have been used in this paper. These data can be downloaded from https://search.earthdata.nasa.gov/search. For example level 2 version 6 multispectral data: https://search.earthdata.nasa.gov/search?q=MOPITT+Derived+ $\mathrm{CO}+($ Near+and+Thermal+Infrared+Radiances $)+\mathrm{V} 006$. Groundbased air quality measurements from Madrid can be downloaded from http://gestiona.madrid.org/azul_internet/html/web/ InformAnalizadoresAccion.icm. The WRF simulation output data are available on request by contacting the corresponding author. EdgarV4.2 emission inventory data are available from http://edgar.jrc.ec.europa.eu/gallery.php?release $=\mathrm{v} 42 \&$ substance $=$ CO\&sector=TOTALS. TNO-MACC-III and TNO-MACC-II data are available on request by contacting the corresponding author. 


\section{The Supplement related to this article is available online at https://doi.org/10.5194/acp-17-14675-2017- supplement.}

Competing interests. The authors declare that they have no conflict of interest.

Acknowledgements. We would like to thank Michiel van der Molen and Ingrid Super for their assistance in using the WRF model and the use of their computer infrastructure and SurfSARA for the use of the Cartesius supercomputing system. The MOPITT data were freely obtained from the NASA Langley Research Center Atmospheric Science Data Center. We would also like to thank the Comunidad de Madrid for free use of their air quality network data.

Edited by: Tim Butler

Reviewed by: two anonymous referees

\section{References}

Abida, R., Attié, J.-L., El Amraoui, L., Ricaud, P., Lahoz, W., Eskes, H., Segers, A., Curier, L., de Haan, J., Kujanpää, J., Nijhuis, A. O., Tamminen, J., Timmermans, R., and Veefkind, P.: Impact of spaceborne carbon monoxide observations from the S-5P platform on tropospheric composition analyses and forecasts, Atmos. Chem. Phys., 17, 1081-1103, https://doi.org/10.5194/acp17-1081-2017, 2017.

Beirle, S., Boersma, K. F., Platt, U., Lawrence, M. G., and Wagner, T.: Megacity Emissions and Lifetimes of Nitrogen Oxides Probed from Space, Science, 333, 1737-1739, 2011.

Berrisford, P., Dee, D., Fielding, K., Fuentes, M., Kållberg, P., Kobayashi, S., and Uppala, S.: ERA-40 Project Report Series, Tech. rep., 2009.

Brent, R. P.: Algorithms for Minimization Without Derivatives, Courier Corporation, 1973.

Choi, Y., Osterman, G., Eldering, A., Wang, Y., and Edgerton, E.: Understanding the contributions of anthropogenic and biogenic sources to CO enhancements and outflow observed over North America and the western Atlantic Ocean by TES and MOPITT, Atmos. Environ., 44, 2033-2042, 2010.

Clerbaux, C., Edwards, D. P., Deeter, M. N., Emmons, L., Lamarque, J.-F., Tie, X. X., Massie, S. T., and Gille, J.: Carbon monoxide pollution from cities and urban areas observed by the Terra/MOPITT mission, Geophys. Res. Lett., 35, L03817-6, https://doi.org/10.1029/2007GL032300, 2008.

Crippa, M., Janssens-Maenhout, G., Dentener, F., Guizzardi, D., Sindelarova, K., Muntean, M., Van Dingenen, R., and Granier, C.: Forty years of improvements in European air quality: regional policy-industry interactions with global impacts, Atmos. Chem. Phys., 16, 3825-3841, https://doi.org/10.5194/acp-163825-2016, 2016.

Deeter, M. N.: Calculation and Application of MOPITT Averaging Kernels, 1-9, available at: https://www.acom.ucar.edu/mopitt/ avg_krnls_app.pdf, 2002.

Deeter, M. N.: MOPITT Geolocation Bias Analysis and Corrections, Tech. rep., 2012.
Deeter, M. N.: MOPITT(Measurements of Pollution in the Troposphere) Version 6 Product User's Guide, 2013a.

Deeter, M. N.: MOPITT V6 Level 2 Data Quality Summary, 1-4, $2013 b$.

Deeter, M. N., Emmons, L. K., Francis, G. L., Edwards, D. P., Gille, J. C., Warner, J. X., Khattatov, B., Ziskin, D., Lamarque, J. F., Ho, S. P., Yudin, V., Attié, J. L., Packman, D., Chen, J., Mao, D., and Drummond, J. R.: Operational carbon monoxide retrieval algorithm and selected results for the MOPITT instrument, J. Geophys. Res., 108, 4399-11, https://doi.org/10.1029/2002JD003186, 2003.

Deeter, M. N., Edwards, D. P., Gille, J. C., and Drummond, J. R.: CO retrievals based on MOPITT nearinfrared observations, J. Geophys. Res., 114, D04303, https://doi.org/10.1029/2008JD010872, 2009.

Deeter, M. N., Martínez Alonso, S., Edwards, D. P., Emmons, L. K., Gille, J. C., Worden, H. M., Pittman, J. V., Daube, B. C., and Wofsy, S. C.: Validation of MOPITT Version 5 thermalinfrared, near-infrared, and multispectral carbon monoxide profile retrievals for 2000-2011, J. Geophys. Res.-Atmos., 118, 6710-6725, 2013.

Deeter, M. N., Martínez-Alonso, S., Edwards, D. P., Emmons, L. K., Gille, J. C., Worden, H. M., Sweeney, C., Pittman, J. V., Daube, B. C., and Wofsy, S. C.: The MOPITT Version 6 product: algorithm enhancements and validation, Atmos. Meas. Tech., 7, 3623-3632, https://doi.org/10.5194/amt-7-3623-2014, 2014.

Deeter, M. N., Martínez-Alonso, S., Gatti, L. V., Gloor, M., Miller, J. B., Domingues, L. G., and Correia, C. S. C.: Validation and analysis of MOPITT CO observations of the Amazon Basin, Atmos. Meas. Tech., 9, 3999-4012, https://doi.org/10.5194/amt-93999-2016, 2016.

de Laat, A. T. J., Aben, I., Deeter, M., Nédélec, P., Eskes, H., Attié, J.-L., Ricaud, P., Abida, R., El Amraoui, L., and Landgraf, J.: Validation of nine years of MOPITT V5 NIR using MOZAIC/IAGOS measurements: biases and long-term stability, Atmos. Meas. Tech., 7, 3783-3799, https://doi.org/10.5194/amt7-3783-2014, 2014

Dudhia, J.: Numerical Study of Convection Observed during the Winter Monsoon Experiment Using a Mesoscale TwoDimensional Model, J. Atmos. Sci., 46, 3077-3107, 1989.

Edwards, D. P., Emmons, L. K., Hauglustaine, D. A., Chu, D. A., Gille, J. C., Kaufman, Y. J., Pétron, G., Yurganov, L. N., Giglio, L., Deeter, M. N., Yudin, V., Ziskin, D. C., Warner, J., Lamarque, J. F., Francis, G. L., Ho, S. P., Mao, D., Chen, J., Grechko, E. I., and Drummond, J. R.: Observations of carbon monoxide and aerosols from the Terra satellite: Northern Hemisphere variability, J. Geophys. Res.-Atmos., 109, D24202, https://doi.org/10.1002/jgrd.50272, 2004.

Ek, M. B., Mitchell, K. E., Lin, Y., Rogers, E., Grunmann, P., Koren, V., Gayno, G., and Tarpley, J. D.: Implementation of Noah land surface model advances in the National Centers for Environmental Prediction operational mesoscale Eta model, J. Geophys. Res., 108, 271-216, 2003.

European Environment Agency: EMEP/EEA air pollutant emission inventory guidebook - 2013, Tech. rep., 2013.

Fioletov, V. E., McLinden, C. A., Krotkov, N., Moran, M. D., and Yang, K.: Estimation of $\mathrm{SO}_{2}$ emissions using OMI retrievals, Geophys. Res. Lett., 38, 1-5, 2011. 
Fu, D., Bowman, K. W., Worden, H. M., Natraj, V., Worden, J. R., Yu, S., Veefkind, P., Aben, I., Landgraf, J., Strow, L., and Han, Y.: High-resolution tropospheric carbon monoxide profiles retrieved from CrIS and TROPOMI, Atmos. Meas. Tech., 9, 2567-2579, https://doi.org/10.5194/amt-9-2567-2016, 2016.

Gamnitzer, U., Karstens, U., Kromer, B., Neubert, R. E. M., Meijer, H. A. J., Schroeder, H., and Levin, I.: Carbon monoxide: A quantitative tracer for fossil fuel CO 2?, J. Geophys. Res., 111, D22302-19, https://doi.org/10.1029/2004JD004727, 2006.

Girach, I. A. and Nair, P. R.: Carbon monoxide over Indian region as observed by MOPITT, Atmos. Environ., 99, 599-609, 2014.

Grell, G. A. and Freitas, S. R.: A scale and aerosol aware stochastic convective parameterization for weather and air quality modeling, Atmos. Chem. Phys., 14, 5233-5250, https://doi.org/10.5194/acp-14-5233-2014, 2014.

Grell, G. A., Peckham, S. E., Schmitz, R., McKeen, S. A., Frost, G., Skamarock, W. C., and Eder, B.: Fully coupled "online" chemistry within the WRF model, Atmos. Environ., 39, 6957-6975, 2005.

Holloway, T., Levy II, H., and Kasibhatla, P.: Global distribution of carbon monoxide, J. Geophys. Res., 105, 12123-12147, 2007.

Hooghiemstra, P. B., Krol, M. C., Bergamaschi, P., Laat de, A. T. J., Werf van der, G. R., Novelli, P. C., Deeter, M. N., Aben, I., and Röckmann, T.: Comparing optimized $\mathrm{CO}$ emission estimates using MOPITT or NOAA surface network observations, J. Geophys. Res., 117, D06309, https://doi.org/10.1029/2011JD017043, 2012a.

Hooghiemstra, P. B., Krol, M. C., Leeuwen van, T. T., Werf van der, G. R., Novelli, P. C., Deeter, M. N., Aben, I., and Röckmann, T.: Interannual variability of carbon monoxide emission estimates over South America from 2006 to 2010, J. Geophys. Res., 117, D15308, https://doi.org/10.1029/2012JD017758, 2012 b.

Hu, X.-M., Klein, P. M., and Xue, M.: Evaluation of the updated YSU planetary boundary layer scheme within WRF for wind resource and air quality assessments, J. Geophys. Res.-Atmos., 118, 10490-10505, 2013.

Hudman, R. C., Murray, L. T., Jacob, D. J., Millet, D. B., Turquety, S., Wu, S., Blake, D. R., Goldstein, A. H., Holloway, J., and Sachse, G. W.: Biogenic versus anthropogenic sources of CO in the United States, Geophys. Res. Lett., 35, L04801, https://doi.org/10.1029/2007GL032393, 2008.

Jacob, D. J., Turner, A. J., Maasakkers, J. D., Sheng, J., Sun, K., Liu, X., Chance, K., Aben, I., McKeever, J., and Frankenberg, C.: Satellite observations of atmospheric methane and their value for quantifying methane emissions, Atmos. Chem. Phys., 16, 14371-14396, https://doi.org/10.5194/acp-16-143712016, 2016.

Jiang, Z., Worden, J. R., Worden, H., Deeter, M., Jones, D. B. A., Arellano, A. F., and Henze, D. K.: A 15-year record of $\mathrm{CO}$ emissions constrained by MOPITT CO observations, Atmos. Chem. Phys., 17, 4565-4583, https://doi.org/10.5194/acp17-4565-2017, 2017.

Kan, H., Chen, R., and Tong, S.: Ambient air pollution, climate change, and population health in China, Environ. Int., 42, 10-19, 2012.

Khalil, M. A. K. and Rasmussen, R. A.: The global cycle of carbon monoxide: trends and mass balance, Vol. 20, John Wiley \& Sons, 1990.
Krol, M., Houweling, S., Bregman, B., van den Broek, M., Segers, A., van Velthoven, P., Peters, W., Dentener, F., and Bergamaschi, P.: The two-way nested global chemistry-transport zoom model TM5: algorithm and applications, Atmos. Chem. Phys., 5, $417-$ 432, https://doi.org/10.5194/acp-5-417-2005, 2005.

Kuenen, J. J. P., Visschedijk, A. J. H., Jozwicka, M., and Denier van der Gon, H. A. C.: TNO-MACC_II emission inventory; a multi-year (2003-2009) consistent high-resolution European emission inventory for air quality modelling, Atmos. Chem. Phys., 14, 10963-10976, https://doi.org/10.5194/acp-14-109632014, 2014.

Lal, S., Naja, M., and Subbaraya, B. H.: Seasonal variations in surface ozone and its precursors over an urban site in India, Atmos. Environ., 34, 2713-2724, https://doi.org/10.1016/S13522310(99)00510-5, 2000.

Landgraf, J., aan de Brugh, J., Scheepmaker, R., Borsdorff, T., Hu, H., Houweling, S., Butz, A., Aben, I., and Hasekamp, O.: Carbon monoxide total column retrievals from TROPOMI shortwave infrared measurements, Atmos. Meas. Tech., 9, 49554975, https://doi.org/10.5194/amt-9-4955-2016, 2016.

Liu, F., Beirle, S., Zhang, Q., Dörner, S., He, K., and Wagner, T.: $\mathrm{NO}_{x}$ lifetimes and emissions of cities and power plants in polluted background estimated by satellite observations, Atmos. Chem. Phys., 16, 5283-5298, https://doi.org/10.5194/acp16-5283-2016, 2016.

Mlawer, E. J., Taubman, S. J., Brown, P. D., Iacono, M. J., and Clough, S. A.: Radiative transfer for inhomogeneous atmospheres: RRTM, a validated correlated-k model for the longwave, J. Geophys. Res.-Atmos., 102, 16663-16682, 1997.

Novelli, P. C., Masarie, K. A., and Lang, P. M.: Distributions and recent changes of carbon monoxide in the lower troposphere, J. Geophys. Res., 103, 15-33, 1998.

Pascal, M., Corso, M., Chanel, O., Declercq, C., Badaloni, C., Cesaroni, G., Henschel, S., Meister, K., Haluza, D., Martin-Olmedo, P., Medina, S., and on behalf of the Aphekom group: Assessing the public health impacts of urban air pollution in 25 European cities: Results of the Aphekom project, Sci. Total Environ., 449, 390-400, https://doi.org/10.1016/j.scitotenv.2013.01.077, 2013.

Pommier, M., McLinden, C. A., and Deeter, M. N.: Relative changes in $\mathrm{CO}$ emissions over megacities based on observations from space, Geophys. Res. Lett., 40, 3766-3771, 2013.

Press, W. H., Teukolsky, S. A., Vetterling, W. T., and Flannery, B. P.: Numerical Recipes in Fortran 77, The Art of scientific computing, 1992.

Rodgers, C. D.: Inverse Methods for Atmospheric Sounding, Theory and Practice, World Scientific, 2000.

Romero-Lankao, P., Qin, H., and Borbor-Cordova, M.: Exploration of health risks related to air pollution and temperature in three Latin American cities, Soc. Sci. Med., 83, 110-118, 2013.

Streets, D. G., Canty, T., Carmichael, G. R., de Foy, B., Dickerson, R. R., Duncan, B. N., Edwards, D. P., Haynes, J. A., Henze, D. K., Houyoux, M. R., Jacob, D. J., Krotkov, N. A., Lamsal, L. N., Liu, Y., Lu, Z., Martin, R. V., Pfister, G. G., Pinder, R. W., Salawitch, R. J., and Wecht, K. J.: Emissions estimation from satellite retrievals: A review of current capability, Atmos. Environ., 77, 1011-1042, 2013.

Strode, S. A., Worden, H. M., Damon, M., Douglass, A. R., Duncan, B. N., Emmons, L. K., Lamarque, J.-F., Manyin, M., Oman, L. D., Rodriguez, J. M., Strahan, S. E., and 
Tilmes, S.: Interpreting space-based trends in carbon monoxide with multiple models, Atmos. Chem. Phys., 16, 7285-7294, https://doi.org/10.5194/acp-16-7285-2016, 2016.

Tewari, M., Chen, F., Wang, W., Dudhia, J., LeMone, M. A., Mitchell, K., Ek, M., Gayno, G., Wegiel, J., and Cuenca, R. H.: Implementation and verification of the unified Noah land surface model in the WRF model, in: the Conference on Weather Analysis and Forecasting 11-15 January 2004, 1-6, Seattle, 2004.

van der Gon, H. D., Hendriks, C., Kuenen, J. J. P., Segers, A., and Visschedijk, A. J. H.: Description of current temporal emission patters and sensitivity of predicted AQ for temporal emission patterns, Tech. rep., 2011.

van Leeuwen, T. T., Peters, W., Krol, M. C., and Werf van der, G. R.: Dynamic biomass burning emission factors and their impact on atmospheric CO mixing ratios, J. Geophys. Res.-Atmos., 118, 6797-6815, 2013.

WHO: Environmental health criteria 213: Carbon monoxide, Tech. rep., 2004.

Worden, H. M., Deeter, M. N., Edwards, D. P., Gille, J. C., Drummond, J. R., and Nédélec, P.: Observations of near-surface carbon monoxide from space using MOPITT multispectral retrievals, J. Geophys. Res., 115, D18314, https://doi.org/10.1029/2010JD014242, 2010.
Worden, H. M., Cheng, Y., and Pfister, G.: Satellite-based estimates of reduced $\mathrm{CO}$ and $\mathrm{CO} 2$ emissions due to traffic restrictions during the 2008 Beijing Olympics, Geophys. Res. Lett., 39, L14802, https://doi.org/10.1029/2012GL052395, 2012.

Yin, Y., Chevallier, F., Ciais, P., Broquet, G., Fortems-Cheiney, A., Pison, I., and Saunois, M.: Decadal trends in global CO emissions as seen by MOPITT, Atmos. Chem. Phys., 15, 1343313451, https://doi.org/10.5194/acp-15-13433-2015, 2015.

Yoon, J., Pozzer, A., Hoor, P., Chang, D. Y., Beirle, S., Wagner, T., Schloegl, S., Lelieveld, J., and Worden, H. M.: Technical Note: Temporal change in averaging kernels as a source of uncertainty in trend estimates of carbon monoxide retrieved from MOPITT, Atmos. Chem. Phys., 13, 11307-11316, https://doi.org/10.5194/acp-13-11307-2013, 2013. 